九州大学学術情報リポジトリ

Kyushu University Institutional Repository

\title{
Integrated microbial enhanced oil recovery (MEOR) simulation: Main influencing parameters and uncertainty assessment
}

Ansah, Eric 0.

Resources Production and Safety Engineering Laboratory, Department of Earth Resources

Engineering, Kyushu University

Sugai, Yuichi

Resources Production and Safety Engineering Laboratory, Department of Earth Resources Engineering, Kyushu University

Nguele, Ronald

Resources Production and Safety Engineering Laboratory, Department of Earth Resources Engineering, Kyushu University

Sasaki, Kyuro

Resources Production and Safety Engineering Laboratory, Department of Earth Resources Engineering, Kyushu University

http://hdl. handle. net/2324/1937165

出版情報: Journal of Petroleum Science and Engineering. 171，pp.784-793，2018-08-04. Elsevier バージョン：

権利関係 : 


\section{Accepted Manuscript}

Integrated microbial enhanced oil recovery (MEOR) simulation: Main influencing parameters and uncertainty assessment

Eric O. Ansah, Yuichi Sugai, Ronald Nguele, Kyuro Sasaki

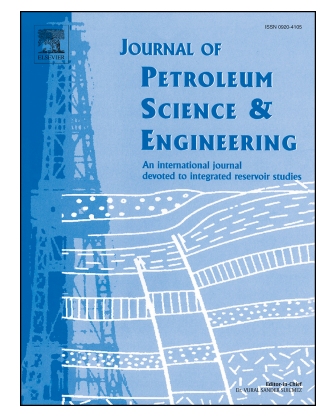

PII:

S0920-4105(18)30671-5

DOI:

10.1016/j.petrol.2018.08.005

Reference: PETROL 5185

To appear in: Journal of Petroleum Science and Engineering

Received Date: 22 May 2018

Revised Date: 28 June 2018

Accepted Date: 2 August 2018

Please cite this article as: Ansah, E.O., Sugai, Y., Nguele, R., Sasaki, K., Integrated microbial enhanced oil recovery (MEOR) simulation: Main influencing parameters and uncertainty assessment, Journal of Petroleum Science and Engineering (2018), doi: 10.1016/j.petrol.2018.08.005.

This is a PDF file of an unedited manuscript that has been accepted for publication. As a service to our customers we are providing this early version of the manuscript. The manuscript will undergo copyediting, typesetting, and review of the resulting proof before it is published in its final form. Please note that during the production process errors may be discovered which could affect the content, and all legal disclaimers that apply to the journal pertain. 


\title{
Integrated Microbial Enhanced Oil Recovery (MEOR) Simulation: Main Influencing Parameters and Uncertainty Assessment
}

\author{
Eric O. Ansah ${ }^{1^{*}}$, Yuichi Sugai ${ }^{1}$, Ronald Nguele ${ }^{1}$ and Kyuro Sasaki ${ }^{1}$ \\ ${ }^{1}$ Resources Production and Safety Engineering Laboratory, Department of Earth Resources \\ Engineering, Kyushu University, Japan.
}

(*) Corresponding author: ansahericbroni@gmail.com/2TE17561M@ s.kyushu-u.ac.jp

\begin{abstract}
The present study investigated the ability of a thermophilic anaerobic microbe (herein coded as AR80) for MEOR with the further objective to quantify the uncertainty of production forecast in terms of the cumulative probability distribution. A series of core flood experiments conducted in water-flooded Berea sandstone showed that up to $51 \%$ of initial oil-in-place was recovered when the plugs were treated with AR80 and shut-in for 14 days. Mainly, the oil recovery mechanisms were attributed to viscosity enhancement, wettability changes, permeability and flow effects. Matching the laboratory data using artificial intelligence: the optimized cumulative oil recovery could be achieved at an enthalpy of 894.2 $\mathrm{J} / \mathrm{gmol}$, Arrhenius frequency of 8.3 , residual oil saturation of $20 \%, \log$ of capillary number at microbe flooding stage of -1.26 , and also depicted a history match error less than $3 \%$. Therefrom, a sensitivity analysis conducted on reservoir shut-in period effect on oil recovery revealed that a relatively shorter shut-in period is recommended to warrant early incremental oil recovery effect for economical purposes. In addition, MEOR could enhance the oil recovery significantly if a larger capillary number (between $10^{-5}$ and $10^{-3.5}$ ) is attained. Per probabilistic estimation, MEOR could sustain already water-flooded well for a set period of time. This study showed that there is a $20 \%$ frequency of increasing the oil recovery by above $20 \%$ when a mature water-flooded reservoir is further flooded with AR80 for 2 additional years. Lastly, it was demonstrated herein that increasing the nutrient (yeast extract) concentration (from $0.1-1 \%$ weight) had less or no significant effect on the oil viscosity and subsequent recovery.
\end{abstract}

\section{Keywords:}

Artificial Intelligence; Capillary Number; Enthalpy; Microbial Enhanced Oil Recovery; Monte Carlo Simulation; Response Surface Methodology 


\section{EXPERIMENT}

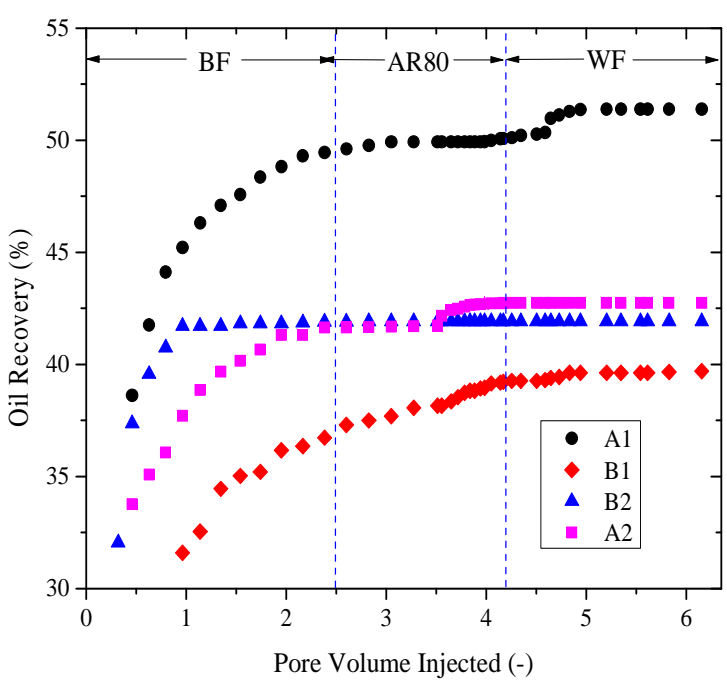

LOGISTIC GROWTH MODEL

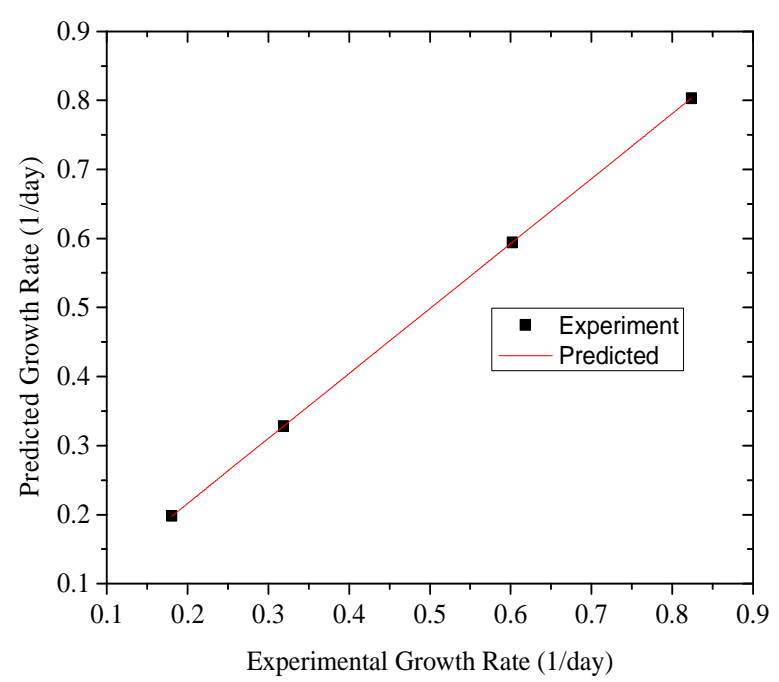

NUMERICAL

SIMULATION
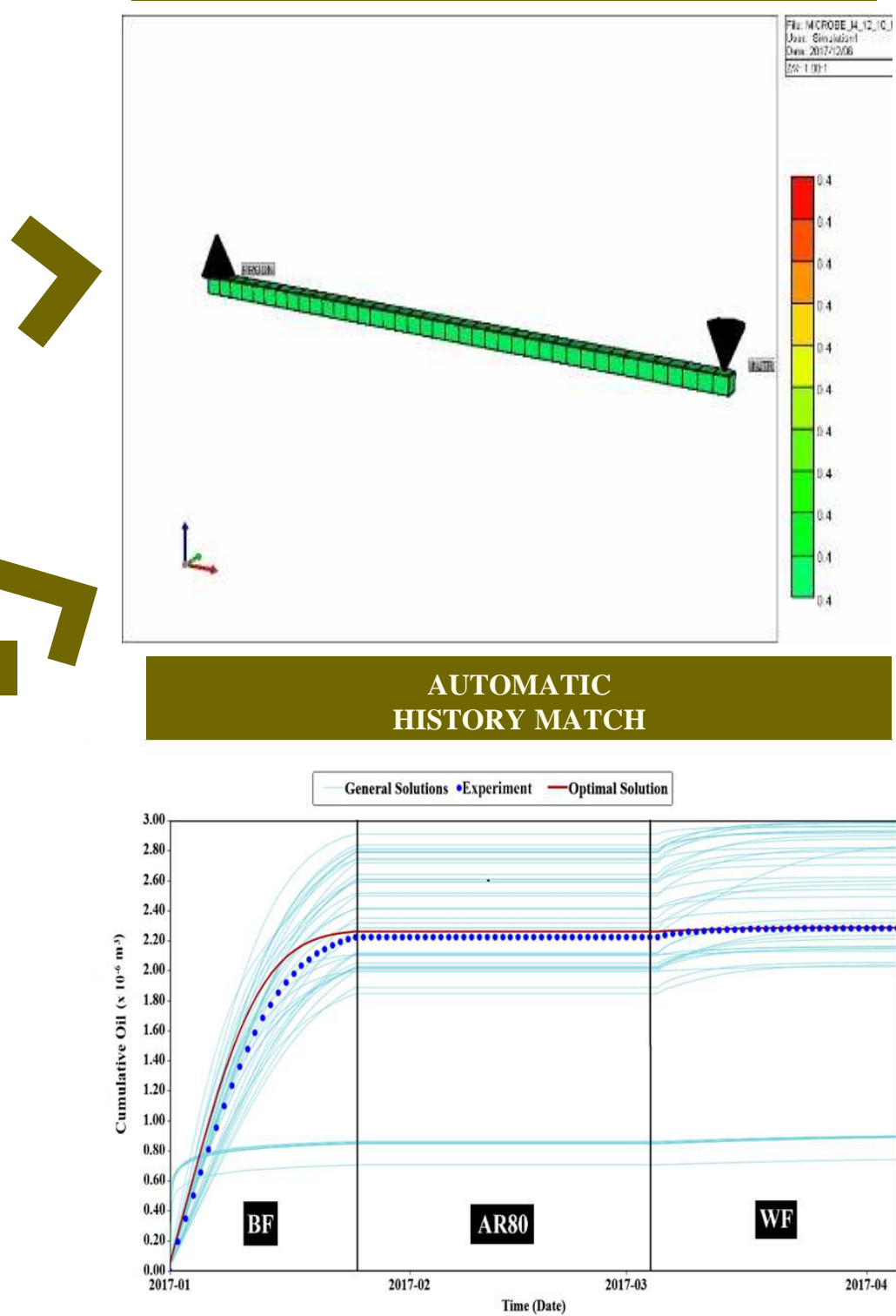

MANUAL

HISTORY MATCH

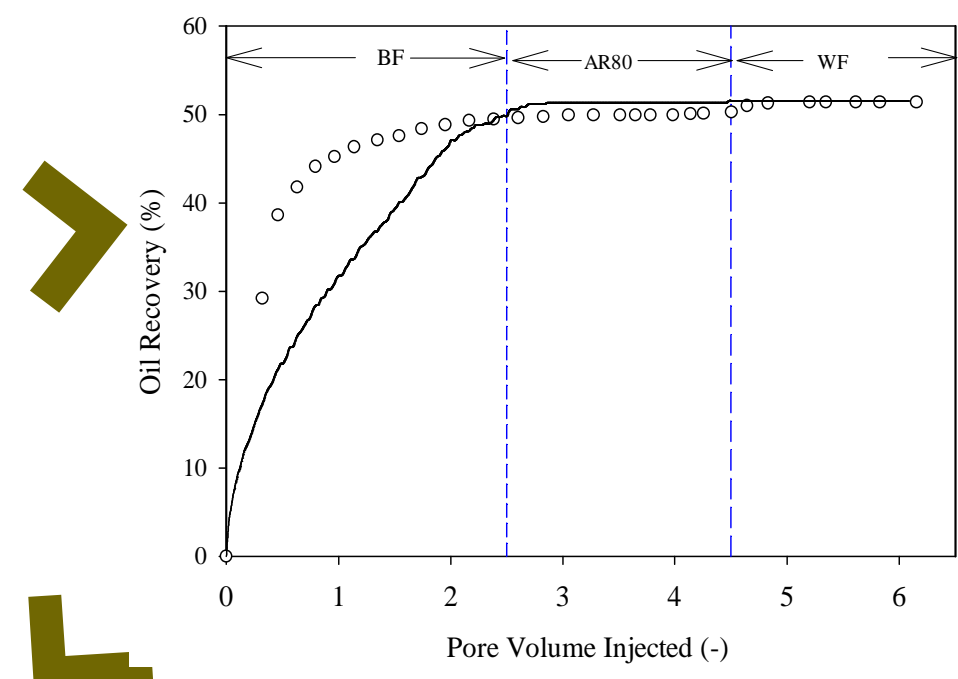

SENSITIVITY ANALYSIS

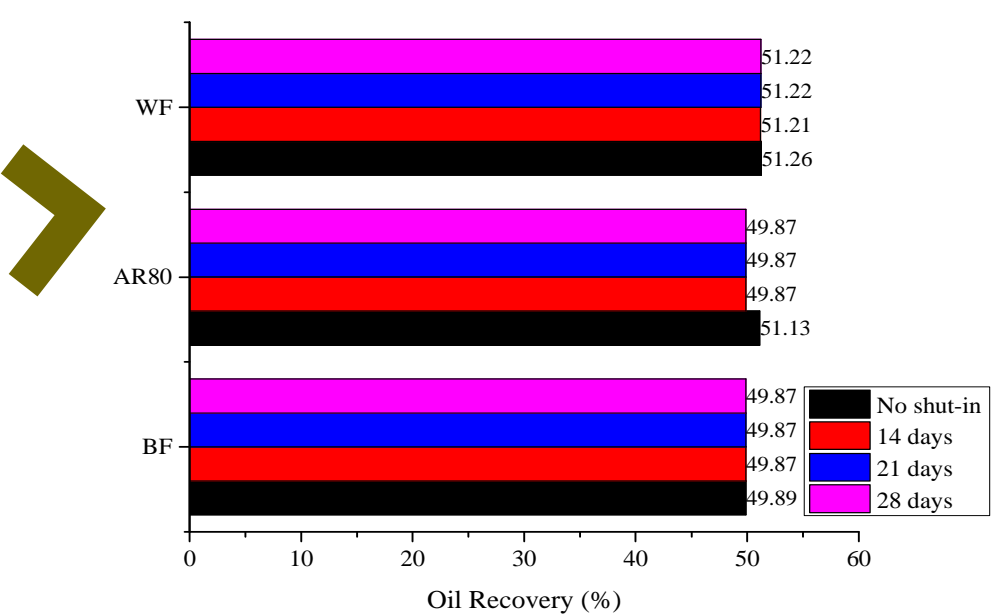




\begin{abstract}
The present study investigated the ability of a thermophilic anaerobic microbe (herein coded as AR80) for MEOR with the further objective to quantify the uncertainty of production forecast in terms of the cumulative probability distribution. A series of core flood experiments conducted in water-flooded Berea sandstone showed that up to $51 \%$ of initial oil-in-place was recovered when the plugs were treated with AR80 and shut-in for 14 days. Mainly, the oil recovery mechanisms were attributed to viscosity enhancement, wettability changes, permeability and flow effects. Matching the laboratory data using artificial intelligence: the optimized cumulative oil recovery could be achieved at an enthalpy of 894.2 $\mathrm{J} / \mathrm{gmol}$, Arrhenius frequency of 8.3 , residual oil saturation of $20 \%, \log$ of capillary number at microbe flooding stage of -1.26 , and also depicted a history match error less than $3 \%$. Therefrom, a sensitivity analysis conducted on reservoir shut-in period effect on oil recovery revealed that a relatively shorter shut-in period is recommended to warrant early incremental oil recovery effect for economical purposes. In addition, MEOR could enhance the oil recovery significantly if a larger capillary number (between $10^{-5}$ and $10^{-3.5}$ ) is attained. Per probabilistic estimation, MEOR could sustain already water-flooded well for a set period of time. This study showed that there is a $20 \%$ frequency of increasing the oil recovery by above $20 \%$ when a mature water-flooded reservoir is further flooded with AR80 for 2 additional years. Lastly, it was demonstrated herein that increasing the nutrient (yeast extract) concentration (from $0.1-1 \%$ weight) had less or no significant effect on the oil viscosity and subsequent recovery.
\end{abstract}

\title{
Keywords:
}

Artificial Intelligence; Capillary Number; Enthalpy; Microbial Enhanced Oil Recovery; Monte Carlo Simulation; Response Surface Methodology 
Nomenclature

\begin{tabular}{|ll|}
\hline DTRAPW & Log of capillary number interpolant at water flooding stage \\
DTRAPY & Log of capillary number interpolant at microbe flooding stage \\
ENTHALPY & Enthalpy of microbe reaction \\
FREQFRAC & The frequency of microbe reaction \\
MFRAC_YEAST & Slug size of yeast extract \\
REACT_TEMP & The reaction of microbe reaction \\
SORW & Residual oil saturation to water \\
TINJW & The temperature of injection fluid \\
krocw & Oil relative permeability adopted at water flooding stage \\
krwiro & Water relative permeability adopted at water flooding stage \\
krocw1 & Oil relative permeability adopted at microbe flooding stage \\
krwiro1 & Water relative permeability adopted at microbe flooding stage \\
BF & Brine flush \\
WF & Water Flush \\
A & Arrhenius factor \\
R & Molar gas constant \\
T & Reaction temperature \\
E & Enthalpy of microbe reaction \\
Prob. & Probability \\
Latin & \\
$\mu_{m a x}$ &
\end{tabular}




\section{Introduction}

Microbial enhanced oil recovery (MEOR) has been touted as the salvager recovery method for stripper wells in the future (Govreau et al., 2013). In that, it has been proven easy to develop and maintain since there is no need to change existing production facilities for both primary and secondary oil recovery stages (Ansah et al., 2018a). Per this view, stripper wells can be great candidates for MEOR economically, to mobilize and push out the trapped oil left in these reservoirs (Rashedi et al., 2012; Govreau et al., 2013). This is also possible as a result of the abundance of microbes in oil reservoirs, their ability to grow and produce bioproduct as well as the cheap nature of nutrients to stimulate microbe growth (Bryant and Douglas,1998). Nonetheless, the above can only happen if the MEOR phenomenon is wellunderstood such that field applications are heightened. Moreover, there is a high possibility of achieving heightened MEOR field applications if MEOR injection scheme and operations are designed to avoid unforeseen issues during field implementation. Up to date, the reported challenges include $(i)$ the absence of commercial numerical simulators that can cover MEOR completely and evaluate the mechanism relative to field upscale, (ii) the absence of techniques monitoring the activities of the targeted microbes in oil reservoirs, (iii) activation of microbes indigenous to oil reservoir by injecting only low-cost substrates into oil reservoirs and ( $i v$ ) inability to easily find and screen suitable bacteria to produce desired metabolites needed for enhanced oil recovery (Bryant and Burchfield,1989; Sen,2008; Sugai ,2013; Safdel et. al., 2017). Thus, the primary scope of this research is to model systematically, and subsequently, to predict MEOR operations using a known commercial simulator.

Literature, related to MEOR, is well-documented yet incomplete since the mechanisms involved are complicated by interrelated properties of complex microbe-oil-rock interaction, fluid properties and varying operating conditions (Bryant and Lockhart, 2002; Armstrong and Wildenschild, 2012; Karim et al., 2012). Furthermore, the variability of oil reservoirs and fluids so digresses that most generalized conclusions have limited applicability. Considering the volatility of oil price, companies mitigate risk through simulation and optimization methods. Nonetheless, such a specific commercial simulator for MEOR is inexistent per our knowledge. It is essential, therefore, to determine the most economical operating conditions for MEOR operations by reservoir simulation. To support the decision-making process of MEOR project, it is also important to assess quantitatively the uncertainty of its economic forecast. Reservoir characteristics and recovery methods are more complex, while laboratory conventional non-simulation methods are far too simplistic and make several assumptions that might not be true of reservoir conditions (Islam 1990; Mustafiz and Islam, 2008).

Numerous studies have addressed the issue of MEOR simulation and modelling theoretically (Islam, 1990; Islam and Gianetto, 1993; Desouky et al., 1996; Sugai et al., 2007; Nielsen et., 2010; Kaster et al., 2012; Bozorg, 2013; Babatunde, 2014). Recently, attention has been geared towards implementing these theories into commercial simulators such as CMG-Stars, UTCHEM, ECLIPSE, MRST among others. For instance, Coombe et al., (2010) combined CMG- Stars and CMOST to model bacteria well souring activities under injection/production operating conditions. They highlighted the relevance of automatic history matching towards the understanding of microbe activities and the fluid flow paths reservoirs. Likewise, Thrasher et al., (2010) evaluated the steps and field trial risk management of MEOR through laboratory testing and numerical simulation. Using two commercial simulators (CMG-Stars and REVEAL), they stipulated that better understanding of microbes and well performance could reduce uncertainties shrouding MEOR. Spirov et al., (2014) simulated the ability of a thermophilic bacteria to produce gas for MEOR using ECLIPSE. Their study underpinned that the best scenario for MEOR operations is the seldom 
injection of water, not large additions of molasses. Bueltemeier et al., (2014) elaborated a more practical field simulation of MEOR using CMG - Stars and also depicted variable solutions for the microbe growth curve with CMOST. They validated their model, which predicted adsorption, reaction kinetics, metabolites production and finally concluded that biosurfactant and biopolymer are the main influencing metabolites for MEOR activities. Moreover, Amundsen (2015) and Akindipe (2016) demonstrated the simulation of MEOR using MRST. Both of them placed much emphasis on biosurfactant and biopolymer types of MEOR. Lastly, Hosseininoosheri (2016) used UTCHEM to model MEOR and concluded that biomass and biosurfactant are the main bio-products influencing oil recovery. Also, Ansah et. al., (2018b) modelled the effect of an oil-degrading microbe on oil recovery using UTCHEM. Considerations were given to environmental conditions that influence microbial activities but not the uncertainties of MEOR operating parameters.

To predict MEOR operations and increase field applications of the process, several questions must be addressed. Past investigations, one way or the other, failed to highlight aptly MEOR assessment and forecasting in a known commercial reservoir simulator. Also, quantification of uncertainties associated with physical and operating parameters affecting MEOR process was unaddressed in past research. Thus, the present study seeks to fill these gaps, elaborating better uncertainty prediction as far as MEOR is concerned.

Specifically, this research aims at investigating the extent to which formation parameters and those that control bacteria growth influence the efficiency of a typical MEOR process. Based on laboratory experimental data, numerical simulation and artificial intelligence, MEOR process is modelled and its associated uncertainties are evaluated. Herein will be investigated the influence of the enthalpy, temperature of reaction among microbe /nutrient dissolution, capillary number, and relative permeability. These formation parameters were selected to highlight their influence on microbe activity and/or oil recovery.

\section{Experimental Section}

\subsection{Materials and methods}

\subsubsection{Bacteria strain type and growth kinetics}

The bacteria type considered for this study was Petrotoga species with 16S rDNA, thereafter coded as AR80. AR80 is thermophilic, halophilic anaerobic microbe, which can grow at diverse environmental conditions. Also, AR80 uses $\mathrm{N}_{2}$ source for growth, preferably yeast extract. The optimum growth conditions, reported elsewhere, were $10 \mathrm{~g} / \mathrm{l}$ salinity, $70{ }^{\circ} \mathrm{C}$ and 6.0 MPa (Purwasena et al., 2009).

\subsubsection{Petroleum fluids}

The crude oil, for this study, was light oil collected from the surface equipment in a Japanese oilfield. The light oil has an API of $33^{\circ}$, a viscosity of $7 \mathrm{cP}$ (measured at $60^{\circ} \mathrm{C}$ ) and a density of 0.958 (measured at $15^{\circ} \mathrm{C}$ ). The candidate formation has a depth and temperature of 1240 $\mathrm{m}$ and $70^{\circ} \mathrm{C}$ respectively.

The composition used for the enrichment (AR80) culture medium prepared from the formation brine, is summarized in Table 1.

$0.1 \mathrm{ml}$ of the brine was inoculated into $50 \mathrm{ml}$ of natural brine medium, consisting brine supplemented with $0.1 \mathrm{~g} / \mathrm{l}$ of yeast extract (supplied by Difco ${ }^{\mathrm{TM}}$, USA) as a nitrogen $\left(\mathrm{N}_{2}\right)$ source and $2 \%$ volume of crude oil as a carbon source for the bacteria. The natural brine medium was sterilized by autoclaving at $121^{\circ} \mathrm{C}$ for 20 minutes with $10 \% \mathrm{CO}_{2}\left(\mathrm{~N}_{2}\right.$ balanced) concentration replacing the headspace air of the sterile serum bottle. Afterwards, it was 
filtered to remove any solid particulates which may cause blockage during the flooding experiment. Herein, the filtered sterilized brine is coded as SB.

\subsubsection{Oil displacement by core flooding}

Core flood test was carried out using averagely 3 pore volumes (PV) of SB, 3 PV of a suspension of AR80 in synthetic culture medium (with a density of $1.0 \times 10^{6}$ cells $/ \mathrm{mL}$ ) and Berea sandstone as a plug. The core was dried to exhaust completely interstitial water prior to vacuum-saturation with SB for establishing the water-wet wettability of core. Afterwards, it was mounted in a Hassle-type core holder and confined at a pressure of 1.0 MPa.

The sandstone was flooded with formation oil until no residual water was observed in the effluent fraction. Then, the oil-bearing plug was autoclaved at $121{ }^{\circ} \mathrm{C}$ for 60 minutes at the end of which the plug was further flooded with $3 \mathrm{PV}$ suspension of AR80 (density of $1.0 \mathrm{x}$ $10^{-06}$ cells $/ \mathrm{mL}$ ) at a constant pressure of $0.02 \mathrm{MPa}$. Afterwards, the plug was shut-in for 14 days at an incubation temperature of $60^{\circ} \mathrm{C}$. The cores were flooded with SB after shut-in for secondary oil recovery. This step was performed until the oil cut in the effluent was less than $1 \%$. The summary of different core flood experiments performed is outlined in Table 2.

\section{Numerical Simulation Considerations}

\subsection{Arrhenius model}

Arrhenius equation has been used severally to describe the temperature effect and other environmental factors on the rate of biochemical reactions (Goldman and Carpenter, 1974; Zwietering et al., 1991; Huang et al.,2011; Bueltemeier et al. 2014). In this study, a simplistic model in which the effect of temperature on microbe growth rates was ascertained using Arrhenius expression. However, the decay rate was not considered primarily because the growth of microbe was assumed to proceed at a maximal rate, which is influenced positively by temperature until impairment (Goldman and Carpenter, 1974). With the knowledge that the change of growth with temperature is expressed as activation energy, the maximum growth as a single rate-limiting step was computed as:

$$
\mu_{\max }=A e^{-\frac{E_{a}}{R T}}
$$

where $\mu_{\max }$ is the maximum microbe growth rate $\left(\right.$ day $\left.^{-1}\right), A$ is the frequency factor $(-), E_{\mathrm{a}}$ is the activation energy $\left(\mathrm{kJ} \mathrm{mol}^{-1}\right), R$ is molar gas constant $\left(\mathrm{kJ} \mathrm{mol}^{-1} \mathrm{~K}^{-1}\right)$ and $T$ is the reaction temperature $(\mathrm{K})$.

The Arrhenius model was later fit into CMG - Stars to model bacteria growth and kinetics. Per the present work, the model was attained by matching maximum growth rate for AR80 derived from experiments.

\subsection{Bacteria reaction}

The stoichiometry reactions, derived from CMG - Stars, were adapted for simplicity to illustrate the dominant process and mechanism of the oil-degrading bacteria. In addition, considerations were made to the aqueous phase components in tracer quantities per the equivalent of water properties (for component density /viscosity). Simple CMG- Stars correlation and component partition coefficient was sufficient for this work. Presumably, the nutrient speciation process and bacteria growth represented by Equation 2 started to occur at the injection well right after injection of the microbe. 
$49 \mathrm{H}_{2} 0+1.001$ microbe +1.1 yeast extract $+1 \mathrm{CO}_{2} \longrightarrow 4.299$ microbe $+4 \mathrm{CH}_{4}$

Brine including nutrient was injected prior to bacteria injection to provide an accommodating environment for microbe growth stage at which the residual oil is degraded following the Equation 3. Dead oil and light in Equation 3 denote heavy (C16 - C20) and light fractions (C10 - C15) of the oil, respectively.

2.15 microbe +1 dead oil $+1 \mathrm{CO}_{2}+1.45 \mathrm{CH}_{4} \longrightarrow 3.34$ light oil

Also, the reactions were assumed to occur in a closed system where there is no influx or leakage from the reservoir fluids and there is complete instantaneous mixing of the injected fluids and reservoir fluids. Furthermore, the bacteria reaction is based on the Arrhenius frequency factor, temperature and concentration of the reacting components.

\subsection{Simulation workflow}

The need for systematic workflow for MEOR simulation is relevant towards envisaging reservoir uncertainties. Thus, history matching (both manual and automatic), sensitivity analysis, and uncertainty analysis using CMG- Stars with CMOST were conducted. This was done to condition a reservoir model to production experimental data as well as quantify the uncertainties of MEOR operations.

\subsubsection{Homogeneous model development}

A one-dimensional reservoir model was considered in this study with dimensions of $7 \mathrm{~m} \times$ $0.1 \mathrm{~m} \times 0.1 \mathrm{~m}$ and was discretized into $40 \times 1 \times 1$ blocks with a total of 40 blocks (Figure 1 ).

The model had one injection well and one production well, which were located in the first and last block respectively. Also, the reservoir length and placement of the wells simulated a five spot connection type. The vertical injection and production wells were perforated through all the layers in the $z$-direction and the injection rate was specified at bottom hole conditions. The injector accepted a constant reservoir fluid rate of $2.00746 \times 10^{-06} \mathrm{~m}^{3} /$ day for the water flooding stage then switched to $2.0597 \times 10^{-06} \mathrm{~m}^{3} /$ day for both the MEOR stage and post-flush stage. The porosity, permeability, injection scenario and other reservoir and production properties used in this model were as from core flooding experiment (Table 3).

In general, the reservoir rock was assumed to be a water-wet rock with only two phases (oil and water) for the simulations.

\section{Results and Discussion}

\subsection{Microbial growth rate modelling}

Figure 2 highlights the mathematical expression used to model the exponential microbe growth phase as well as describes the relationship between temperature and maximum microbe growth rate $\left(\mu_{\max }\right)$

First order, second order and fourth order of the Arrhenius equation have been used to describe the dependency of microbe growth rate on the temperature of the system of microbe reproduction. Figure $2 \mathrm{a}$, maximum microbe growth rate $\left(\mu_{\max }\right)-\mathrm{T}\left({ }^{\circ} \mathrm{C}\right)$, illustrates a satisfactory agreement between the model and data set reported. The agreement between $\mu_{\max }$ 
of the microbe as predicted by the Arrhenius model and the observed growth rates in the independent experiments is presented in Figure $2 b\left(R^{2}=0.94\right)$. This was attained by fitting the experimental data by first order Arrhenius equation presented as:

$$
\mu_{\max }=1.847 e^{-\frac{86.12}{T}}
$$

Therefore, it can be said that Equation 4 can predict the maximum microbe growth rate and temperature relation using similar microbes within the limit of the test conditions of this study.

\subsection{Oil recovery by microbial treatment}

Increase in oil recovery as a result of decreasing residual oil saturation and viscosity showed the effectiveness of the microbial treatment for oil recovery. Figure 3 highlights cumulative oil recovery for brine only (A1 and A2) and microbe plus brine treated (B1 and B2) flooding experiments conducted.

Generally, the oil recovery recorded for the microbe plus treated flooding was higher than the brine only (abiotic) flooding. At the pre-flush stage i.e. BF, the primary oil recovery recorded were 49.9, 41.6, 39.6 and $41.7 \%$ for A1, A2, B1 and B2 respectively. After treating the cores with microbe and shut-in for 14 days, the final oil recovery gradually increased to $51.3 \%$ and $42.8 \%$ for A1 and A2 respectively. This was averagely 5\% higher than the control experiments (39.9\% for B1 and $42 \%$ for B2). It should be noted that due to the highest oil recovery observed for the experiment, $\mathbf{A 1}$, it was adopted for simulation.

\subsection{Oil recovery mechanisms}

In this section, we elaborate on the various mechanisms that led to the incremental oil recovery. The primary goal was to reduce the oil viscosity and residual oil saturation. The residual saturation changed as a function of the capillary number that defines the relative effect of viscous forces versus surface tension acting across an interface between oil and water (Chatzis and Morrow, 1984). Also, the original wettability of the formation and altered wettability during and after MEOR operation influenced the production characteristics in the formation.

We believe all the following mechanisms occurred dependently to ensure a successful MEOR operation by AR80. Nonetheless, the main influencing mechanism can be attributed to the viscosity enhancement. Pressure build-up due to biopolymer production as well as biosurfactant effects on oil recovery was neither observed nor considered in this study.

\subsubsection{Viscosity enhancement}

The viscosity enhancement affected the oil mobility and capillary number (ratio of capillary force to viscous force) and furthermore, the residual oil saturation. We hypotheses that this occurred due to the following mechanisms:

(a.) Hydrocarbon degradation

Viscosity reduction occurred due to the breakdown of long-chain n-alkanes (> C16) to short chain n-alkanes $(<\mathrm{C} 15)$ by AR80 (Purwasena et al., 2010 and Sugai et al., 2012). Purwasena et al. (2010) stipulated that AR80 reduces oil viscosity by $40 \%$ of its original viscosity after few days of incubation. The alkanes $\left(n-\mathrm{C}_{16} \mathrm{H}_{34}\right)$ biodegradation process in the anaerobic environment can be represented by the following global reactions (Jones et al., 2008; Zengler et al., 1999): 


$$
\begin{aligned}
& 4 \mathrm{C}_{16} \mathrm{H}_{34}+64 \mathrm{H}_{2} \mathrm{O} \rightarrow 32 \mathrm{CH}_{3} \mathrm{COO}^{-}+32 \mathrm{H}^{+}+68 \mathrm{H}_{2} \\
& 68 \mathrm{H}_{2}+17 \mathrm{CO}_{2} \rightarrow 17 \mathrm{CH}_{4}+34 \mathrm{H}_{2} \mathrm{O} \\
& 32 \mathrm{CH}_{3} \mathrm{COO}^{-}+32 \mathrm{H}^{+}+64 \mathrm{H}_{2} \mathrm{O} \rightarrow 128 \mathrm{H}_{2}+64 \mathrm{CO}_{2} \\
& 32 \mathrm{CH}_{3} \mathrm{COO}^{-}+32 \mathrm{H}^{+} \rightarrow 32 \mathrm{CH}_{4}+32 \mathrm{CO}_{2}
\end{aligned}
$$

(b.) Effect of acids/solvents produced

The produced acids (e.g. acetic acid) and solvents, during the biodegradation of long-chain n-alkanes as well as due to the yeast extract speciation, affected the viscosity of the oil. The decrease in viscosity ensured increased mobility of the oil through the reservoir and enhanced the capillary number due to low viscous forces. This later resulted in lower residual oil saturation.

(c.) Influence of produced gases due to

i. Hydrocarbon degradation stimulated by yeast extract

The produced gas $\left(\mathrm{CH}_{4}\right.$ and $\left.\mathrm{CO}_{2}\right)$, elaborated in Equation 6 - 9, caused a decrease in oil viscosity. This occurred at the oil-water interphase, at which the gases moved from the aqueous state into the oil phase. Hence, causing a thinning effect of the oil viscosity.

ii. Hydrolysis of yeast extract during fluid/fluid and fluid/rock interaction

The hydrolysis of yeast extract, which was utilized for AR80 growth under anaerobic conditions, resulted in the release of $\mathrm{CH}_{4}$ and $\mathrm{CO}_{2}$ (Soto et al., 2013). Hydrogeochemical reactions highlighting the formation of $\mathrm{CO}_{2}$ and $\mathrm{CH}_{4}$ due to the protonation of carbonate ion are represented by Equations 9 and 10 (Ansah et al.,2018b)

$$
\begin{aligned}
& \mathrm{CO}_{3}^{-2}+2 \mathrm{H}^{+} \leftrightarrow \mathrm{CO}_{2}+\mathrm{H}_{2} \mathrm{O} \\
& \mathrm{CO}_{3}{ }^{-2}+10 \mathrm{H}^{+}+8 \mathrm{e}^{-} \leftrightarrow \mathrm{CH}_{4}+3 \mathrm{H}_{2} \mathrm{O}
\end{aligned}
$$

\subsubsection{Wettability changes}

The incremental oil recovery observed could be attributed to the changes in wettability from a water-wet to more water-wet state. This is explained by these two mechanisms:

(a.) Influence of microbe and biomass adhesion

Wettability alterations can be due to microbe and biomass attachment to the oil/rock surface, thereby reducing the organic carbon concentration and making the surface more water wet (Karimi et al 2012; Youssef et al., 2009). Subsequently, this affected the relative permeability and capillary number by reducing the interfacial tension effects in the reservoir medium. The increased capillary number was good for incremental oil recovery; this was highlighted during the sensitivity analysis in a later section of this study.

(b.) Ion exchange during yeast extract/brine/rock interaction

The effect of divalent and monovalent ion exchange on wettability and relative permeability as well as oil recovery is well investigated (Soraya et al., 2009; Ligthelm et al.,2009; Mugele et al., 2015). Ansah et al. (2018b) explored the effect of yeast extract/brine/rock interaction on wettability due to the various ion 
exchange half reactions occurring between dissolved cations (mainly $\mathrm{Na} / \mathrm{Mg} / \mathrm{Ca}$ ) and the rock surface reversibly. These reactions were partly responsible for the water wet nature of the reservoir, hence, improved oil recovery.

\subsubsection{Permeability enhancement and flow effects}

Enhancement of the reservoir permeability may have facilitated easy oil movement through the porous media. This effect could be as a result of (i) acetic acid and other solvents produced during the breakdown of long chain n-alkanes by AR80 and (ii) carbonic acid and other acids/solvents produced during yeast extract/salt/rock interaction. Ansah et al. (2018b) predicted the dissolution of rock minerals during the injection of yeast extract for microbe growth into injected into a 1D single water- wet core occupied by reservoir brine and equilibrated with quartz, k-feldspar and kaolinite. This dissolution action might as well have been enhanced by the microbe activity.

Also, biomass is known to change the flow pattern by blocking some pore and pore throats (Youssef et al., 2009). Formation of biomass, during AR80 growth, can be said to have clogged preferential pathways, thereby increasing sweeping efficiency. This was further highlighted during the reservoir simulation.

\subsection{History match of laboratory data}

Figure 4 highlights the history match results for the laboratory experimental data.

A fairly good match was achieved at the MEOR flooding and water chase stages but not at the pre-flush or water flooding stage (Figure 4a). This could be due to the input data for the relative permeability, water and oil saturation, and capillary number interpolant among other data sets. Due to the intuitive and qualitative nature of manual history match, automatic history match with a quantitative approach was conducted (Figure 4b). Automatic history match (HM) was performed to have a range of plausible HM solution other than one precise HM results. The optimized cumulative oil recovery could be achieved for an enthalpy of 894.2 J/gmol, Arrhenius frequency of 8.3, residual oil saturation of $20 \%$ and a log of the capillary number at microbe flooding stage of -1.26 . Also, the best match was at run \#44 with a minimum global error of $3 \%$ (Table 4 ).

A close comparison between the manual and automatic history match shows improvement in the matching quality and an average history match error less than $10 \%$. These observations are in agreement with expected indications of better history matching results using artificial intelligence. Per probabilistic estimation, MEOR could sustain already water-flooded well for a set period of time. Prior to the results presented above, there is a $20 \%$ frequency of increasing the oil recovery by above $20 \%$ when a mature water-flooded reservoir further flooded with AR80 for 2 additional years.

\section{Sensitivity Analysis}

In order to establish optimum conditions for MEOR operations, we performed sensitivity analysis. Both the effect of shut-in period and dynamic viscosity reduction on oil recovery were investigated. Also, the effect of selected reservoir parameters on oil recovery, emphasizing capillary number sensitivity effect on viscous forces alteration on oil recovery is highlighted. 


\subsection{Shut- in period effect}

To evaluate the influence of shut-in period on oil recovery, 3 scenarios (involving 14,21,28 days) were studied. The results are shown in Figure 5.

It can be observed that shut-in period increment has no effect on oil recovery. For instance, increasing the shut-in period from 14 days (as performed experimentally in this study) to 21 days caused no significant effect on the total oil recovery. This is despite the early hike in oil recovery for the shut-in period of 14 days during water chase. The shut-in period can be said to have less or no significant effect on oil viscosity reduction responsible for oil recovery though it could have a considerable effect on wettability, IFT and gas production after the shut-in period (Behlulgil et al.,1992). Per this, a relatively shorter shut-in period to warrant early incremental oil recovery effect for economical purposes is recommended.

\subsection{Dynamic viscosity reduction}

Figure 6 highlights the distribution of $\mathrm{CO}_{2}$, produced microbe in addition to light oil production, before and at the end of the simulation with time.

Per this present study, the $\mathrm{CO}_{2} / \mathrm{CH}_{4}$ levels for the wells do show an increasing value until viscosity effects bring it down. This can also be an indication for $\mathrm{CO}_{2}$ plus $\mathrm{CH}_{4}$ propagation through the reservoir (Ansah et al., 2018b) (Figures 6a). This is clearly elaborated in Figure $6 \mathrm{c}$, the production of light oil increases gradually at the water flooding stage but increases sharply after microbe injection and shut-in period. Figure $6 \mathrm{~b}$ shows a sharp increase in microbe production during the shut-in period which decreases right afterwards.

Specifically, in this study, the decrease in oil viscosity at the water flooding stage is as a result of the yeast extract speciation which is bound to lead to $\mathrm{CO}_{2}$ and $\mathrm{CH}_{4}$ production (Soto et., 2013). Whereas, at the MEOR flooding stage, the viscosity reduction is accounted for by mechanisms as explained earlier. These two mechanisms, therefore, account for the higher oil recovery caused by the increase of the capillary number as a consequence of the relatively low IFT as well as oil viscosity reduction.

\subsection{Capillary number sensitivity}

Figure 7 displays that there is a strong correlation between oil recovery and DTRAP (log of the capillary number) and subsequently, capillary pressure.

In all cases, as the capillary number increases (DTRAP from -3.5 to -5 ), oil recovery increased from 51.2 to $58 \%$. Conclusively, the high capillary number was noted to yield very low residual oil saturation, hence, high oil recovery. With the knowledge that the capillary number characterizes the relation of viscous forces to interfacial tension, an increase in capillary number suggests a positive flow by permitting water to imbibe into small pores whiles displacing oil into large pores for recovery. Also, capillary pressure is seen to be a function of the non-wetting phase (oil). At log of capillary number (DTRAP) equals -3.5, the trapped non-wetting phase become mobile and is pushed out of the pores. Thus, low oil saturation is thereby influenced by high capillary number. Also, relative permeability and wettability action can be related to microbe adhesion to the rock surface, even though adhesion was not considered in this study. As earlier stated, bacteria are known to form patch layer on oil/rock surface and in effect, remove organic compounds and materials such as $\mathrm{CO}$ resulting in wettability changes. (Karimi et al., 2012). 


\subsection{Yeast extract effect on oil recovery}

Microbe nutrient (precisely yeast extract) and microbe injection slug size were varied using CMOST to access its effect on MEOR recovery. In contrast to results presented by Sugai et al., (2014), increasing the yeast extract concentration (from $0.1-1 \%$ weight) has less or no significant effect on the oil viscosity and subsequent recovery (Figure 8).

Hence, excess yeast extract concentration is not a prerequisite for oil recovery increment; rather just the adequate economical amount is needed for maximum microbe growth and metabolite production. This is so because, in a closed system, the microbe cells adapt to a fixed concentration in the reservoir at any particular growth. We attest yeast extract might affect cumulative oil recovered when it is steadily (or continuously fed) thereby resulting in increasing microbe growth.

\section{Summary and Conclusion}

This research investigated MEOR to predict and quantify the uncertainty of production forecast in terms of a cumulative probability distribution by using core - flooding experiments, artificial intelligence and Monte Carlo simulation techniques. History match error for the model was less than 3\% using an artificial intelligence tool. This study has demonstrated that through systematic simulation considering both physical and biochemical parameters, the uncertainties in predicting MEOR can be enlightened. The key findings are:

1. More broadly, the results contribute to knowledge about the potential of successful utilization of a Petrotoga species for MEOR and the methanogenic degradation of longer-chain n- alkanes by AR80 present in anaerobic and thermophilic environments. The results indicated AR80 treated experiments produced almost 6\% higher oil recovery than abiotic experiments.

2. The main oil recovery mechanisms can be attributed to viscosity enhancement, wettability changes, permeability and flow effects.

3. Reservoir shut-in period during MEOR operations have less or no significant effect on oil viscosity reduction responsible for oil recovery.

4. The model results demonstrated that MEOR could enhance the oil recovery significantly if a larger capillary number (between $10^{-5}$ and $10^{-3.5}$ ) is attained. Also, there is a $20 \%$ frequency of increasing the oil recovery by above $20 \%$ when a mature water-flooded reservoir further flooded with AR80 for 2 additional years.

5. Increasing the yeast extract concentration (from 0.1- $1.1 \%$ weight) had less or no significant effect on the oil viscosity and subsequent recovery because, in a closed system, the microbe cells adapt to a fixed concentration in the reservoir at any particular growth.

6. The combined supply of $\mathrm{CO}_{2}$ and yeast extract (protein - rich matter) to oil field formation waters resulted in the stimulation of microbe growth and subsequent oil biodegradation by AR80 at reservoir conditions (anaerobic and thermophilic) conditions. Also, the results confirmed the production of $\mathrm{CH}_{4}$ and $\mathrm{CO}_{2}$ by both biogenic means and the hydrolysis of yeast extract used to simulate microbe growth.

7. Further work is therefore desired to elaborate the combined injection of $\mathrm{CO}_{2}$ and a protein-rich matter into a reservoir since this could represent an economic approach to reduce $\mathrm{CO}_{2}$ emissions and EOR. Also, enlightenment on the methanogenic pathway 
by AR80 and other petrotoga species in this regard is relevant to biotechnology application for heavy oil recovery.

\section{Acknowledgements}

The authors would like to extend a hand of appreciation to the Computer Modelling Group for their support towards using CMG-Stars and CMOST. Also, much thankfulness to the Ministry of Education, Science and Technology (MEXT) of Japan for supporting this research.

\section{Funding}

This work was financially supported by JSPS KAKENHI; Grant Number JP16K14524.

\section{Declaration of interest}

The authors declare no conflict of interest.

\section{References}

Akindipe, D., 2016. Evaluation of Microbial Enhanced Oil Recovery using the MRST Simulator, Master's thesis, NTNU.

Armstrong, R.T. and Wildenschild, D., 2012. Investigating the pore-scale mechanisms of microbial enhanced oil recovery. Journal of Petroleum Science and Engineering, 94, pp.155164.

Ansah E.O, Sugai Y., and Sasaki K.,2018a. Geological tectonics and physio-chemical metrics as screening criteria for MEOR applicability in West Africa transform regional oil wells - a review. Int. J. Petroleum Engineering,3(2), pp. 116 - 137.

Ansah E.O, Sugai Y., and Sasaki K.,2018b. Modeling microbial-induced oil viscosity reduction: Effect of temperature, salinity and nutrient concentration. Petroleum Science and Technology, pp. 1 - 7, doi: 10.1080/10916466.2018.1463253

Amundsen, A., 2015. Microbial Enhanced Oil Recovery-Modeling and Numerical Simulations, Master's thesis, NTNU.

Babatunde, S.O., 2014. Modeling of Oil Reservoirs with Focus On Microbial Induced Effects, Master's thesis, The University of Bergen.

Behlulgil, K., Mehmetoglu, T. and Donmez, S., 1992. Application of microbial enhanced oil recovery technique to a Turkish heavy oil. Applied Microbiology and Biotechnology, 36(6), pp.833-835.

Bozorg, A., 2013. Interactions between Biofilm Growth and Fluid Flow in Porous Media, Doctoral dissertation, University of Calgary.

Bryant, R. S. and Burchfield, T. E.,1989. Review of microbial technology for improving oil recovery. SPE Reservoir Engineering, 4(2), pp. 151-154. doi: 10.2118/16646-PA.

Bryant, R.S. and Douglas, J., 1988. Evaluation of microbial systems in porous media for EOR. SPE Reservoir Engineering, 3(02), pp.489-495.

Bryant, S.L. and Lockhart, T.P., 2002. Reservoir engineering analysis of microbial enhanced oil recovery. SPE Reservoir Evaluation \& Engineering, 5(05), pp.365-374.

Bueltemeier, H., Alkan, H. and Amro, M., 2014, March. A new modeling approach to MEOR calibrated by bacterial growth and metabolite curves. In SPE EOR Conference at Oil and Gas West Asia. March 31- April 2, Muscat, Oman. 
Chatzis, I. and Morrow, N.R., 1984. Correlation of capillary number relationships for sandstone. Society of Petroleum Engineers Journal, 24(05), pp.555-562.

Coombe, D.A., Jack, T., Voordouw, G., Zhang, F., Clay, B. and Miner, K., 2010. Simulation of bacterial souring control in an Alberta heavy-oil reservoir. Journal of Canadian Petroleum Technology, 49(05), pp.19-26.

Desouky, S.M., Abdel-Daim, M.M., Sayyouh, M.H. and Dahab, A.S., 1996. Modelling and laboratory investigation of microbial enhanced oil recovery. Journal of Petroleum Science and Engineering, 15(2-4), pp.309-320.

Goldman, J.C. and Carpenter, E.J., 1974. A kinetic approach to the effect of temperature on algal growth. Limnology and Oceanography, 19(5), pp.756-766.

Govreau, B., Marcotte, B., Sheehy, A., Town, K., Zahner, B., Tapper, S. and Akintunji, F., 2013. Field applications of organic oil recovery-a new MEOR method. In Enhanced Oil Recovery Field Case Studies, pp. 581-614.

Hosseininoosheri, P., 2016. Further model development and application of UTCHEM for microbial enhanced oil recovery and reservoir souring, Doctoral dissertation, University of Texas.

Huang, L., Hwang, A. and Phillips, J. 2011 Effect of temperature on microbial growth ratemathematical analysis: The Arrhenius and Eyring-Polanyi connections, Journal of Food Science, 76(8), pp. 553-560. doi: 10.1111/j.1750-3841.2011.02377.

Islam, M.R. 1990. Mathematical modeling of microbial enhanced oil recovery. 65th SPE Annual. Tech. Conf. Exhibition. Sept. 21-26, New Orleans, La., USA, SPE 20480, pp. 159168.

Islam, M.R. and Gianetto, A., 1993. Mathematical modelling and scaling up of microbial enhanced oil recovery. Journal of Canadian Petroleum Technology, 32(04).

Jones, D.M., Head, I.M., Gray, N.D., Adams, J.J., Rowan, A.K., Aitken, C.M., Bennett, B., Huang, H., Brown, A., Bowler, B.F.J. and Oldenburg, T., 2008. Crude-oil biodegradation via methanogenesis in subsurface petroleum reservoirs. Nature, 451(7175), pp.176-180.

Kaster, K.M., Hiorth, A., Kjeilen-Eilertsen, G., Boccadoro, K., Lohne, A., Berland, H., Stavland, A. and Brakstad, O.G. 2012. Mechanisms involved in microbially enhanced oil recovery. Transport in Porous Media, 91(1), pp.59-79.

Karimi, M., Mahmoodi, M., Niazi, A., Al-Wahaibi, Y. and Ayatollahi, S. 2012. Investigating wettability alteration during MEOR process, a micro/macro scale analysis. Colloids and Surfaces B: Biointerfaces, 95, pp.129-136.

Ligthelm, D.J., Gronsveld, J., Hofman, J., Brussee, N., Marcelis, F. and van der Linde, H., 2009. Novel waterflooding strategy by manipulation of injection brine composition. In EUROPEC/EAGE conference and exhibition. 8-11 June, Amsterdam, The Netherlands.

Miranda-Tello, E., Fardeau, M.L., Joulian, C., Magot, M., Thomas, P., Tholozan, J.L. and Ollivier, B. 2007. Petrotoga halophila sp. nov., a thermophilic, moderately halophilic, fermentative bacterium isolated from an offshore oil well in Congo. International Journal of Systematic and Evolutionary Microbiology, 57(1), pp.40-44.

Mugele, F., Bera, B., Cavalli, A., Siretanu, I., Maestro, A., Duits, M., Cohen-Stuart, M., Van Den Ende, D., Stocker, I. and Collins, I. 2015. Ion adsorption-induced wetting transition in oil-water-mineral systems. Scientific Reports, 5, pp.10519.

Mustafiz, S. and Islam, M.R. 2008. State-of-the-art petroleum reservoir simulation. Petroleum Science and Technology, 26(10-11), pp.1303-1329.

Nielsen, S.M., Shapiro, A., Stenby, E.H. and Michelsen, M.L. 2010. Microbial enhanced oil recovery-advanced reservoir simulation. Doctoral dissertation, Technical University of Denmark (DTU). 
Purwasena, I.A., Sugai, Y. and Sasaki, K. 2009. Estimation of the Potential of an OilViscosity-Reducing Bacteria, Petrotoga Isolated from an Oilfield for MEOR. In International Petroleum Technology Conference. 7 - 9 December, Doha, Qatar.

Rashedi, H., Yazdian, F. and Naghizadeh, S. 2012. Microbial enhanced oil recovery. In Introduction to Enhanced Oil Recovery (EOR) Processes and Bioremediation of OilContaminated Sites. InTech.

Sen, R., 2008. Biotechnology in petroleum recovery: The microbial EOR. Progress in Energy and Combustion Science, 34(6), pp.714-724.

Safdel, M., Anbaz, M.A., Daryasafar, A. and Jamialahmadi, M. 2017. Microbial enhanced oil recovery, a critical review on worldwide implemented field trials in different countries. Renewable and Sustainable Energy Reviews, 74, pp.159-172.

Spirov, P., Ivanova, Y. and Rudyk, S. 2014. Modelling of microbial enhanced oil recovery application using anaerobic gas-producing bacteria, Petroleum Science, 11(2), pp. 272-278. doi: 10.1007/s12182-014-0340-7.

Soto, M., Méndez, R. and Lema, J.M. 1993. Methanogenic and non-methanogenic activity tests. Theoretical basis and experimental setup. Water Research, 27(8), pp.1361-1376.

Soraya B, Malick C, Philippe C, Bertin HJ, Hamon G. 2009. Oil recovery by low-salinity brine injection: Laboratory results on outcrop and reservoir cores. In SPE Annual Technical Conference and Exhibition. 4-7 October, New Orleans, Louisiana, USA.

Sugai, Y., Komatsu, K., Sasaki, K., Mogensen, K. and Bennetzen, M.V. 2014. Microbialinduced oil viscosity reduction by selective degradation of long-chain alkanes. In Abu Dhabi International Petroleum Exhibition and Conference. 12 - 15 November, Abu Dhabi, UAE.

Sugai, Y. 2013 Challenges to advance Microbial EOR to a practical EOR, Journal of the Japanese Association for Petroleum Technology, 78(6), pp. 455-462.

Sugai, Y., Purwasena, I.A., Sasaki, K., Fujiwara, K., Hattori, Y. and Okatsu, K., 2012. Experimental studies on indigenous hydrocarbon-degrading and hydrogen-producing bacteria in an oilfield for the microbial restoration of natural gas deposits with $\mathrm{CO} 2$ sequestration. Journal of Natural Gas Science and Engineering, 5, pp.31-41.

Sugai, Y., Hong, C., Chida, T. and Enomoto, H. 2007. Simulation studies on the mechanisms and performances of MEOR using a polymer producing microorganism Clostridium sp. TU-15A. In Asia Pacific Oil and Gas Conference and Exhibition. 30 October - 1 November, Jakarta, Indonesia.

Thrasher, D.R., Puckett, D.A., Pospisil, G., Vance, I., Davies, A., Beattie, G., Boccardo, G. and Jackson, S.C. 2010. MEOR from lab to field. In SPE Improved Oil Recovery Symposium. 24 - 28 April 2010, Tulsa, Oklahoma, USA.

Youssef, N., Elshahed, M.S. and McInerney, M.J., 2009. Microbial processes in oil fields: culprits, problems, and opportunities. Advances in Applied Microbiology, 66, pp.141-251.

Zwietering, M.H., De Koos, J.T., Hasenack, B.E., De Witt, J.C. and Van't Riet, K. 1991. Modelling of bacterial growth as a function of temperature. Applied and Environmental Microbiology, 57(4), pp.1094-1101.

Zengler, K., Richnow, H.H., Rosselló-Mora, R., Michaelis, W. and Widdel, F., 1999. Methane formation from long-chain alkanes by anaerobic microorganisms. Nature, 401(6750), pp.266-269. 


\section{List of figures and tables}

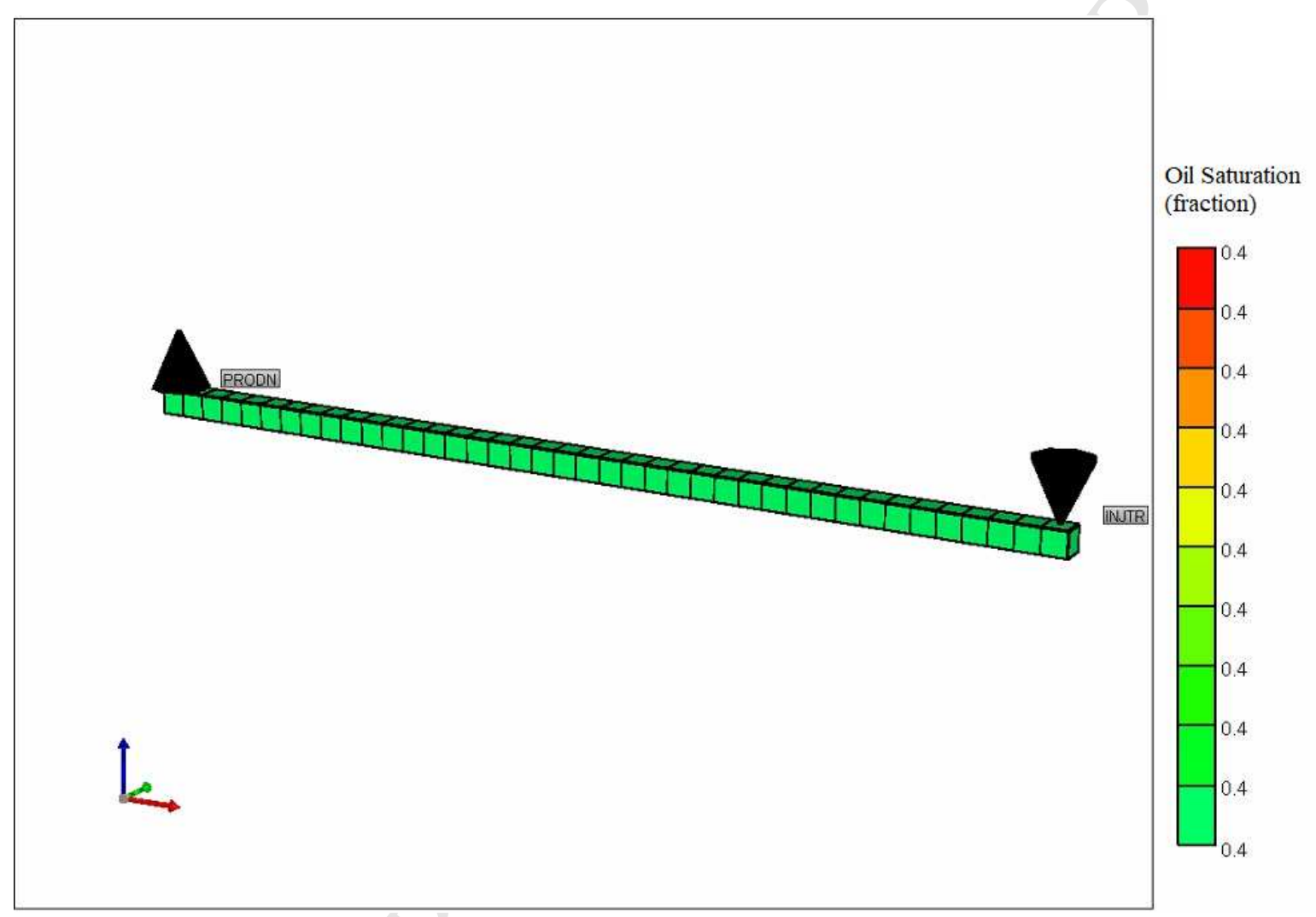

Figure 1 Homogeneous laboratory core model used in this study elaborating the injection (INJTR) and production (PRODN) wells 


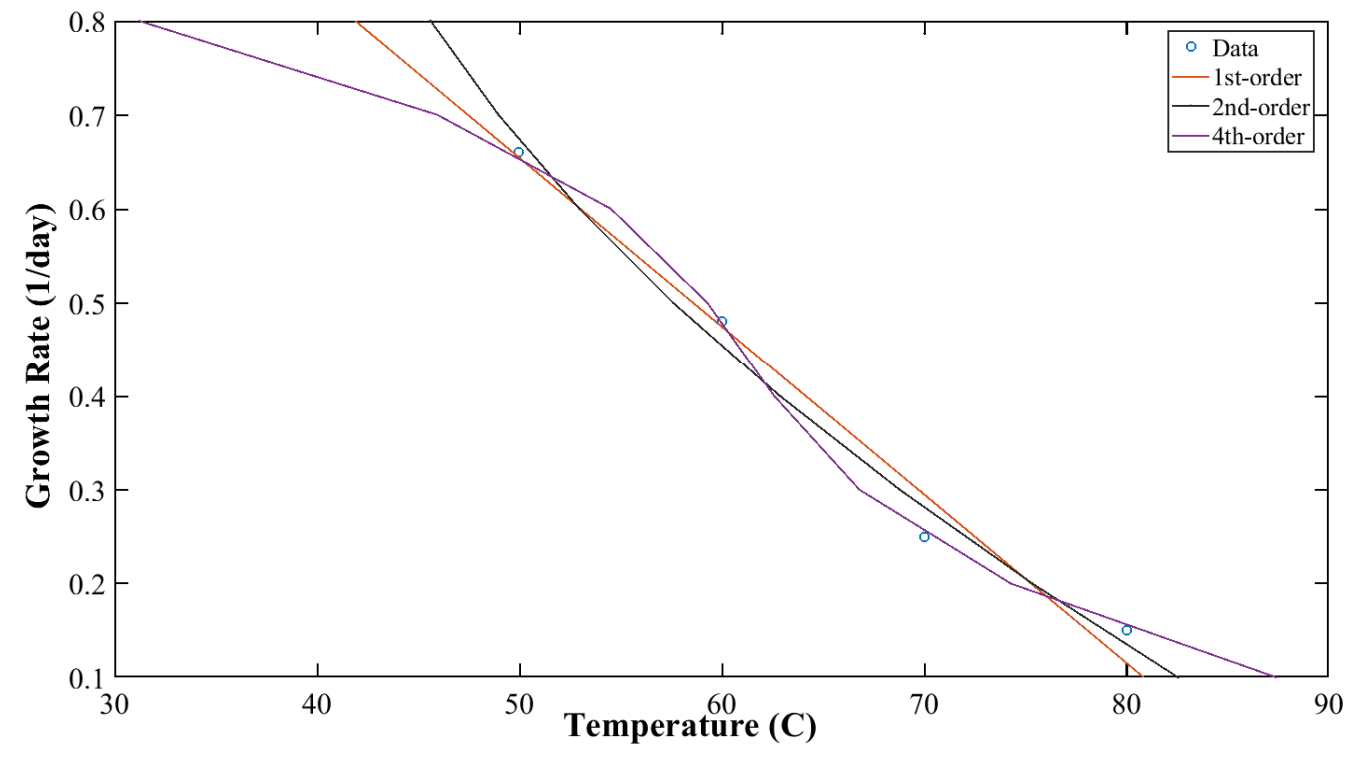

(a) Growth rate and temperature relations elaborating on $1^{\text {st }}, 2^{\text {nd }}$ and $4^{\text {th }}$ thermodynamic reaction orders.

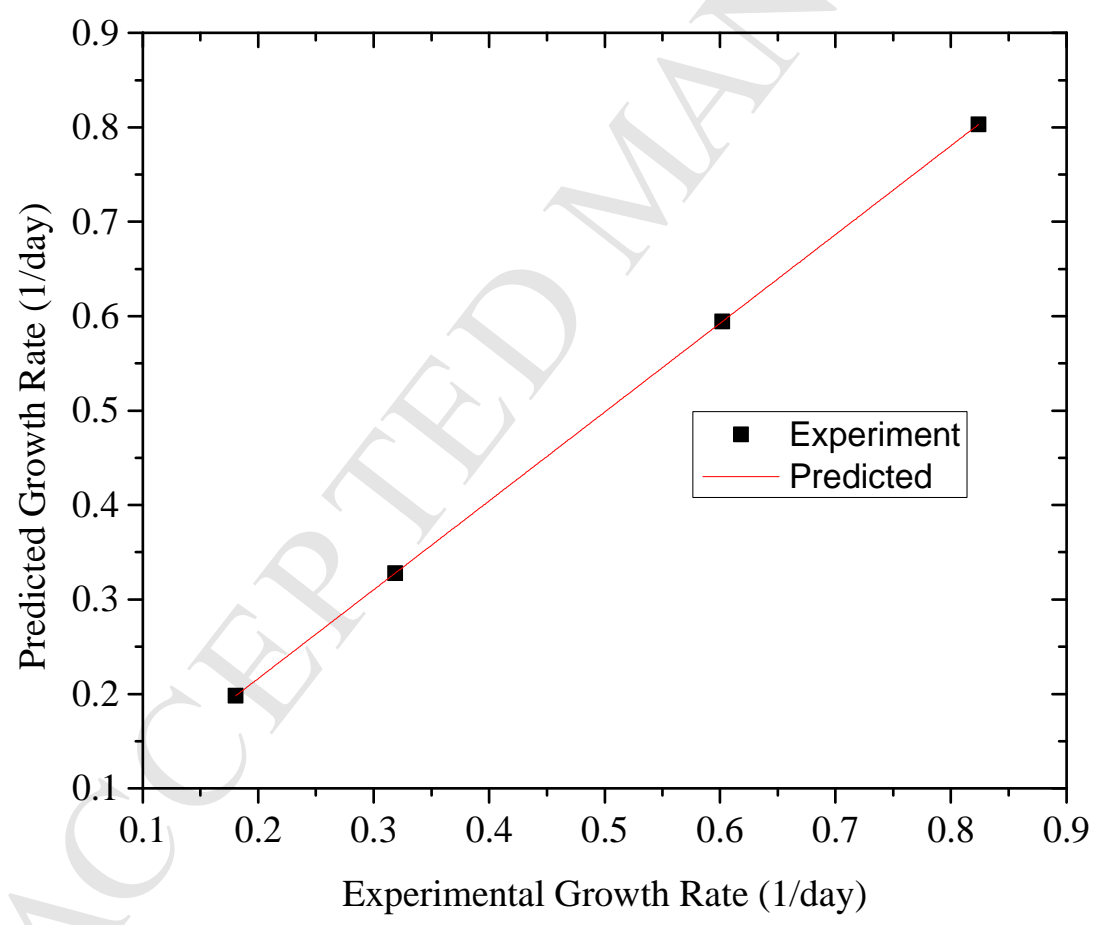

(b) Experimental and predicted microbe growth modelling.

Figure 2 Arrhenius reaction model. 


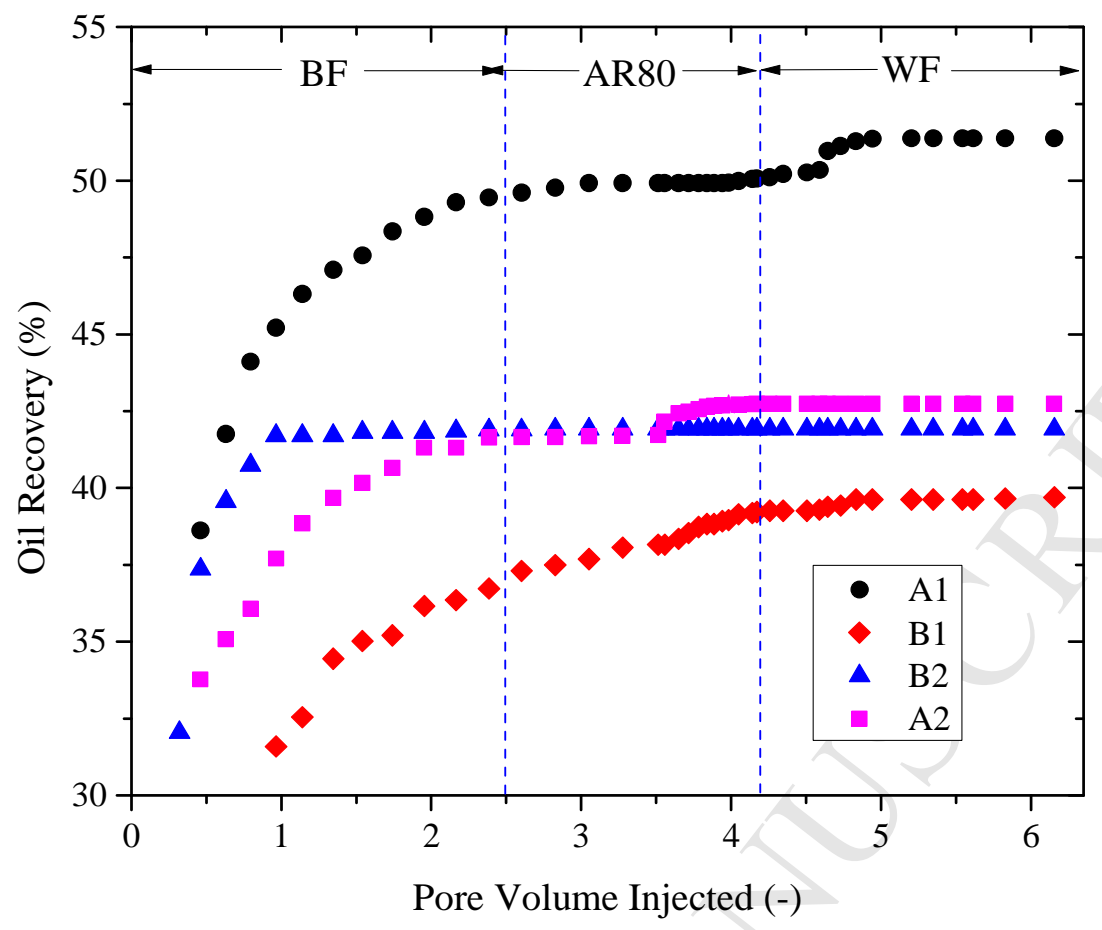

Figure 3 Core flooding results for only brine flooding (A1 and A2) and microbial flooding (E1 and E2)

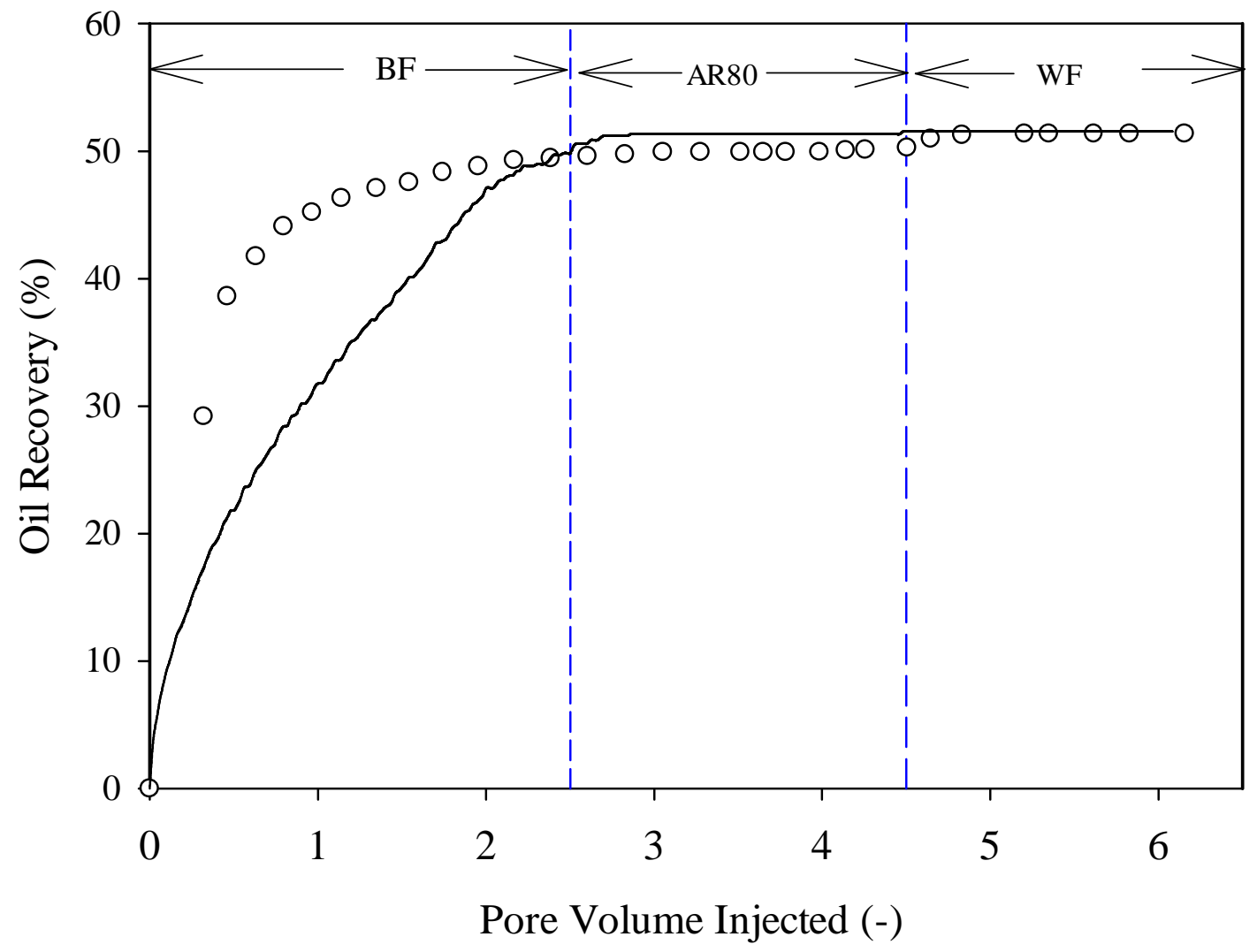


(a) Manual history matching for the pre-flush (BF), microbe injection and well shut-in (AR80) as well as the post - flush stages (WF) of the laboratory data.

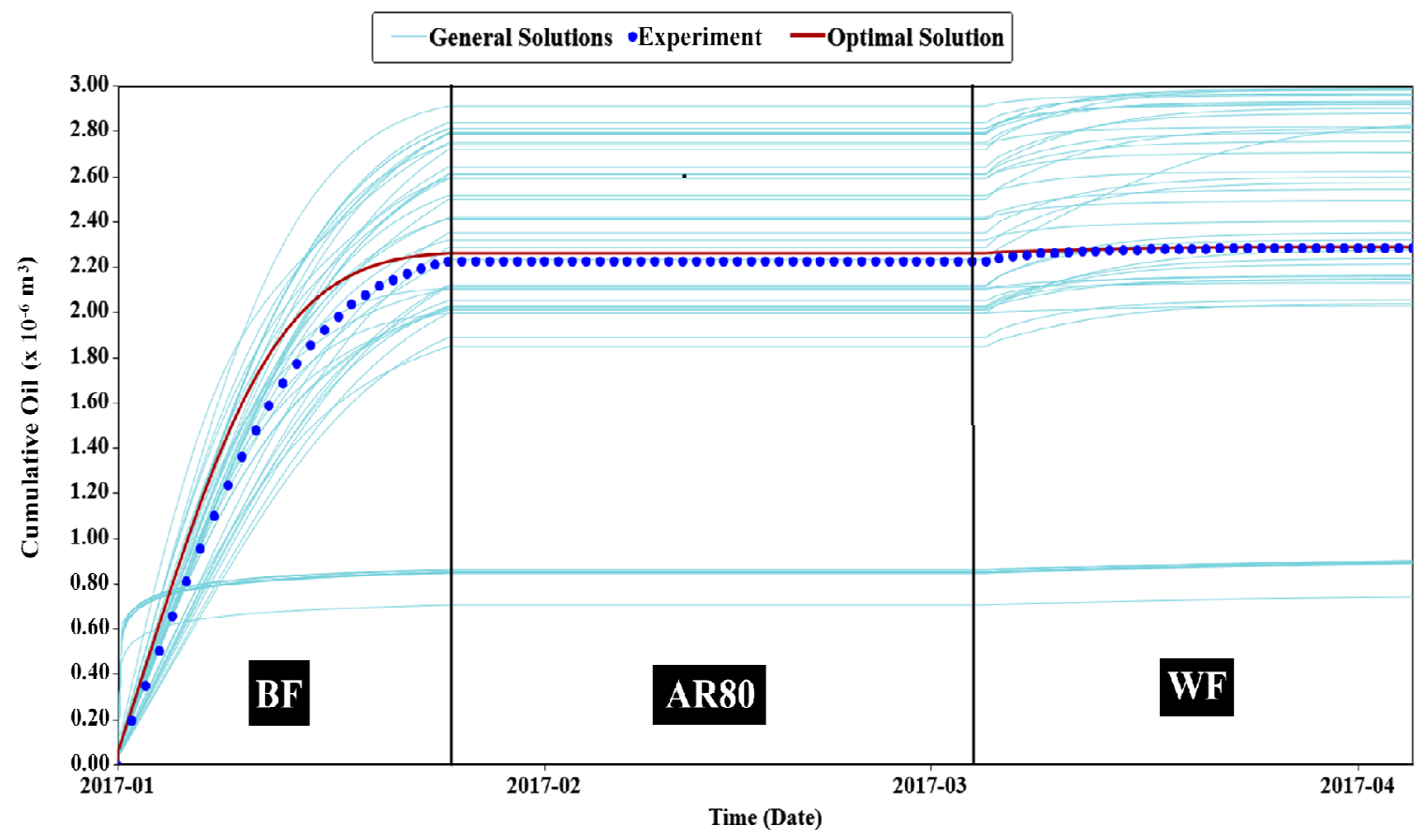

(b) Automatic history match of laboratory data showing a plausible range of results using artificial intelligence.

Figure 4 History match of laboratory data

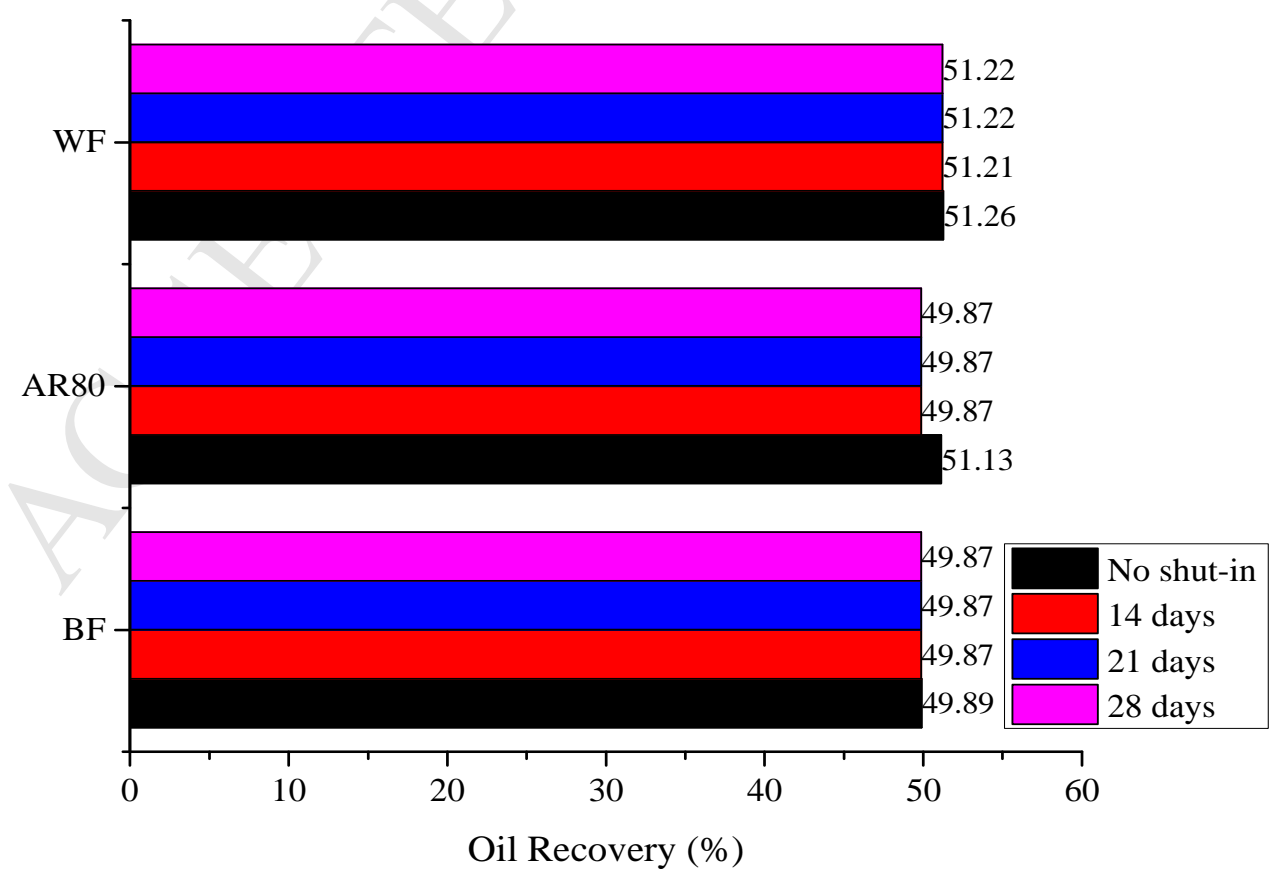

Figure 5 Effect of the shut-in period on oil recovery for 14, 21 and 28 shut-in days. Shut -in involved shutting both the producer and injector wells for the stipulated time. 


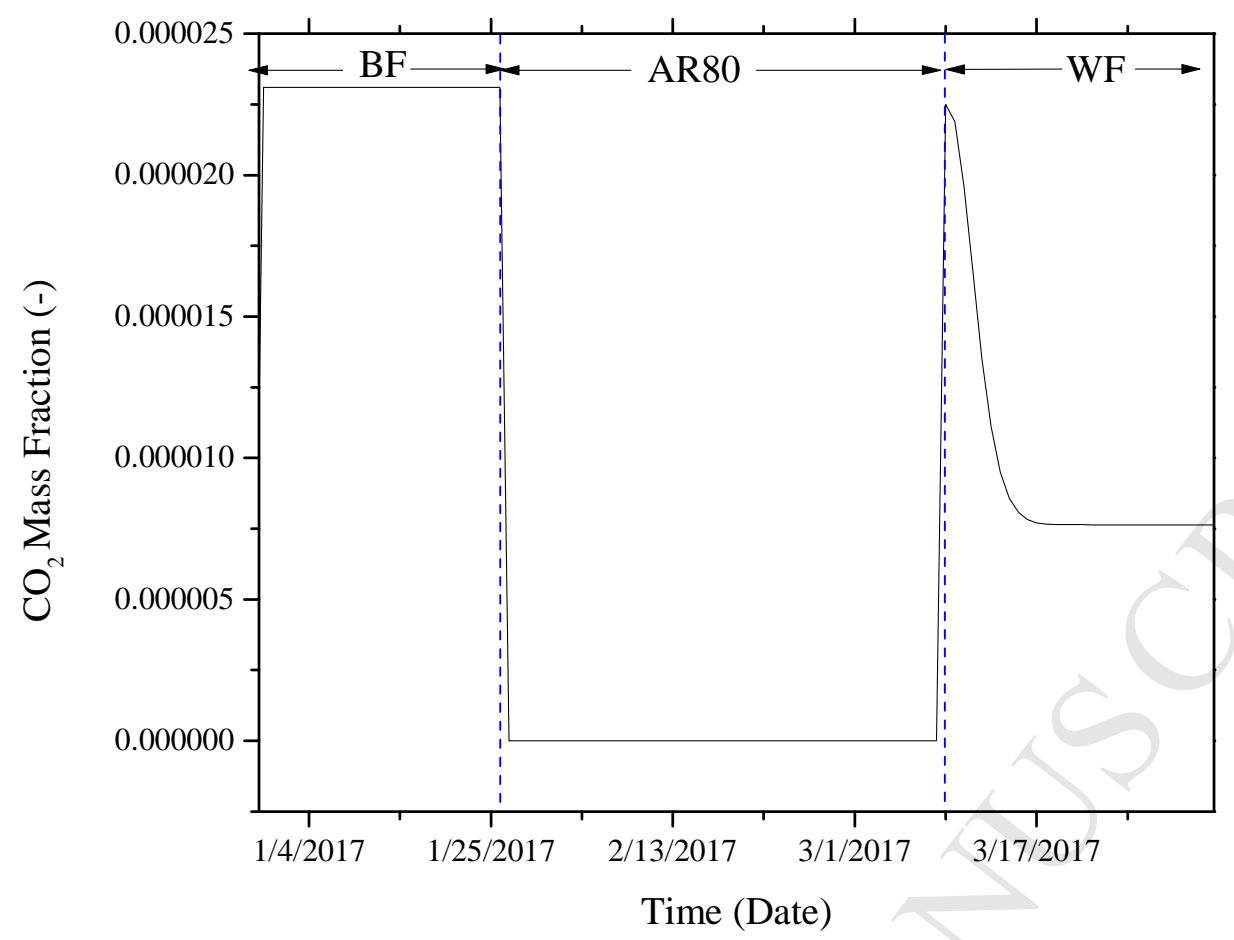

(a) Dynamic change of $\mathrm{CO}_{2}$ mass fraction at different stages of flooding.

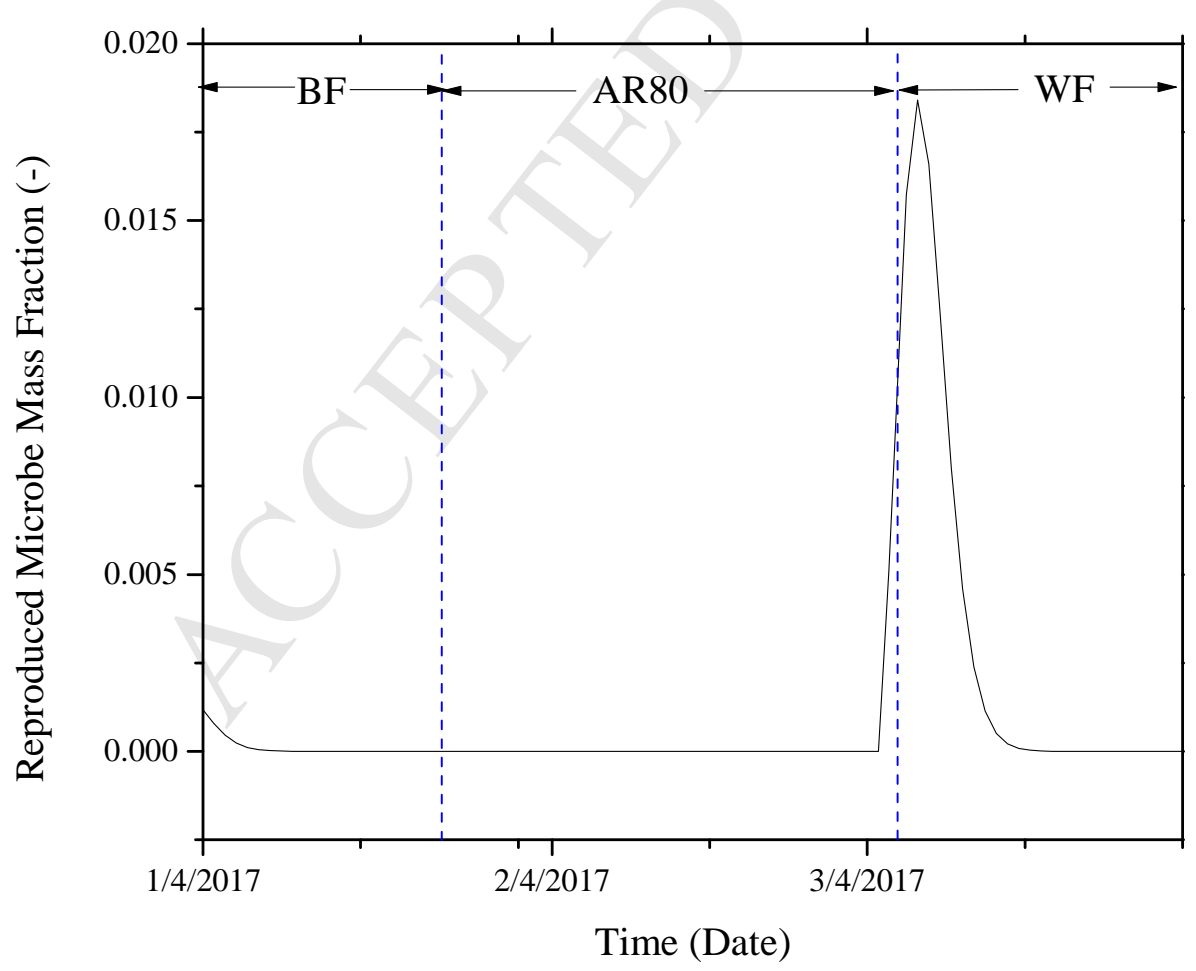

(b) Microbe reproduction against time at different stages of flooding. 


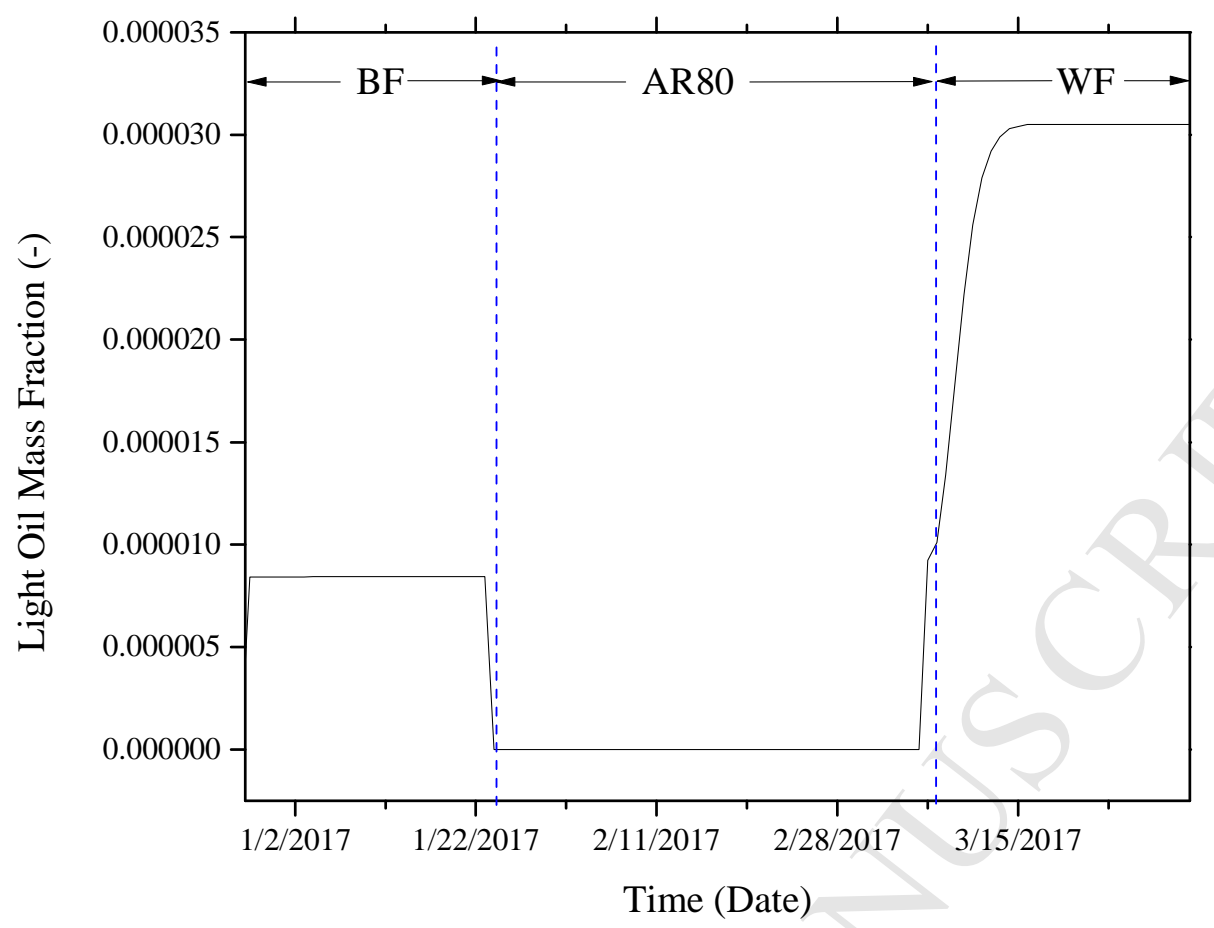

(c) Dynamic change of light oil mass fraction different stages of flooding Figure 6 Effect of bacteria growth and dissolved as a function of viscosity reduction

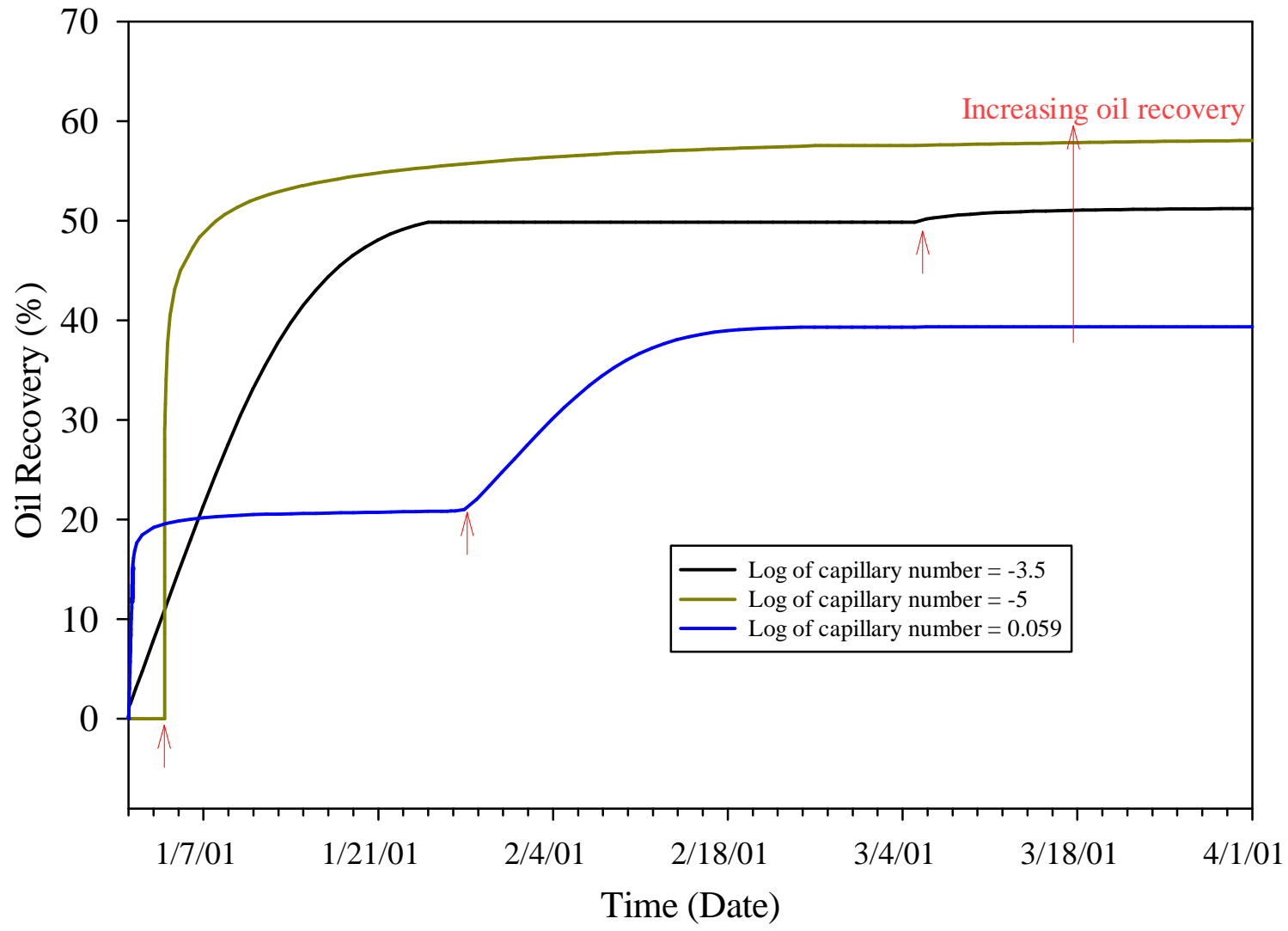

Figure 7 Relationship between oil recovery and capillary number 


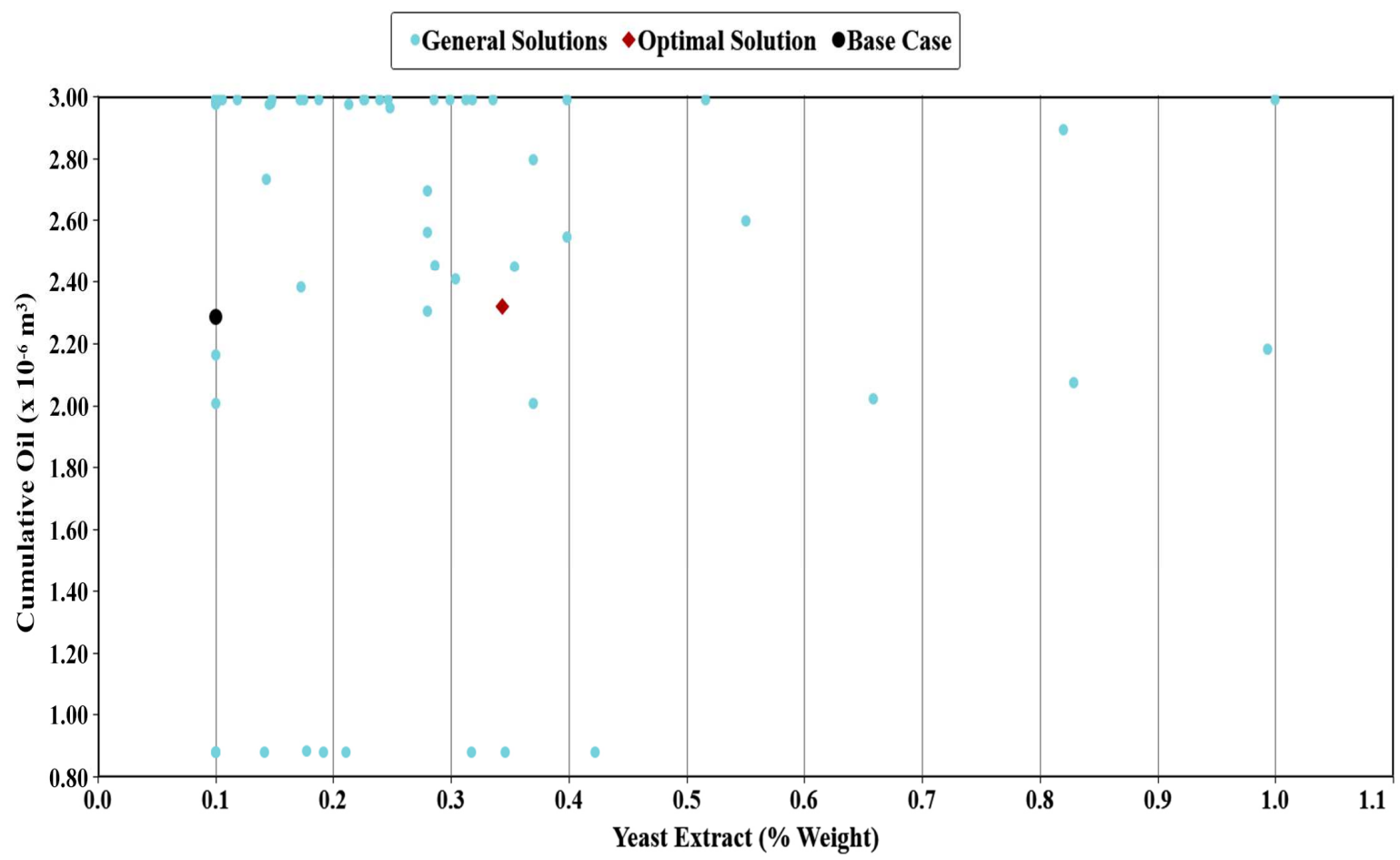

Figure 8 Yeast extract weight percent effect on oil recovery 
Table 1 Ionic composition of brine used for enrichment (of AR80) culture medium ${ }^{\text {a }}$

\begin{tabular}{|c|c|c|c|c|}
\hline $\mathrm{Na}^{+}: 3075$ & $\mathrm{~K}^{+}: 30$ & $\mathrm{Ca}^{2+}: 5$ & $\mathrm{Mg}^{2+}: 3$ & $\mathrm{NH}_{4}^{+}: 15$ \\
\hline $\mathrm{Cl}^{-}: 2500$ & $I^{-}: 1.5$ & $\mathrm{HBO}_{2}{ }^{2-}: 250$ & $\mathrm{HCO}^{3-}: 4000$ & \\
\hline T-Fe: 2 & $\begin{array}{l}\text { Acetic acid: } \\
4.3\end{array}$ & Formic acid: 2.2 & Lactic acid: $<0.1$ & $\begin{array}{l}\text { Propionic acid: < } \\
0.1\end{array}$ \\
\hline
\end{tabular}

${ }^{\mathrm{a}}$ Composition is given in ppm

Table 2 Core flooding experiments data

\begin{tabular}{|c|c|c|c|c|}
\hline \multicolumn{5}{|c|}{ Berea sandstone and oil properties } \\
\hline Experiment code & A1 & A2 & B1 & B2 \\
\hline Treatment & \multicolumn{3}{|c|}{ Treated by AR80 } & Control \\
\hline Core length $(\mathrm{cm})$ & \multicolumn{4}{|c|}{7.0} \\
\hline Core diameter $(\mathrm{cm})$ & \multicolumn{4}{|c|}{0.38} \\
\hline Pore volume $(\mathrm{mL})$ & 16.48 & 16.31 & 16.26 & 16.55 \\
\hline Porosity (\%) & 20.65 & 20.44 & 20.37 & 20.73 \\
\hline Absolute permeability (mD) & \multicolumn{4}{|c|}{300} \\
\hline Oil viscosity (cP) & \multicolumn{4}{|c|}{7.0 at $60{ }^{\circ} \mathrm{C}$} \\
\hline Initial oil saturation $(\%)$ & 38.65 & 37.40 & 35.55 & 34.75 \\
\hline \multicolumn{5}{|c|}{ Pre-flush (BF) } \\
\hline $\mathrm{PV}$ injected during $\mathrm{BF}$ & 3.0 & 3.0 & 3.0 & 3.0 \\
\hline Average injection rate $(\mathrm{PV} / \mathrm{hr})$ & 1.17 & 1.40 & 1.56 & 1.35 \\
\hline \multicolumn{5}{|c|}{ AR80 Flooding } \\
\hline PV of injected culture & \multicolumn{2}{|c|}{3.0 with AR80 } & \multicolumn{2}{|c|}{3.0 without microbe } \\
\hline Average injection rate $(\mathrm{PV} / \mathrm{hr})$ & \multicolumn{4}{|c|}{1.10} \\
\hline Shut-in period & \multicolumn{4}{|c|}{14 days } \\
\hline \multicolumn{5}{|c|}{ Water chase (WF) } \\
\hline PV injected during WF & 3.0 & 3.16 & 3.0 & 3.0 \\
\hline Average injection rate $(\mathrm{PV} / \mathrm{hr})$ & 0.80 & 1.10 & 1.34 & 1.00 \\
\hline
\end{tabular}


Table 3 Simulation input data

Formation Fluid Injection Data

Treatment

Treated with AR80

$\mathrm{PV}$ injected during BF

PV injected culture medium with AR80

Shut-in period (days)

PV injected during WF

2.5

\section{Core flood Data}

Reservoir size (m)

$7 \times 0.1 \times 0.1$

Number of grid blocks $(\mathrm{cm})$

$40 \times 1 \times 1$

Grid block size $(\mathrm{cm})$

$0.2 \times 0.1 \times 0.1$

Initial reservoir temperature $\left({ }^{\circ} \mathrm{C}\right)$

70

Initial reservoir pressure $(\mathrm{MPa})$

Pore volume (mL)

Porosity (\%)

Absolute Permeability (mD)

Oil Viscosity at $60{ }^{\circ} \mathrm{C}(\mathrm{cP})$

Initial water saturation $(\%)$

Initial Oil Saturation (\%)

Table 4 Selected experimental runs showing combination of parameters, cumulative oil recovery and history match error

\begin{tabular}{cccccccc}
\hline & $\begin{array}{c}\text { DTRAP } \\
\text { ID }\end{array}$ & $\begin{array}{c}\text { DTRAP } \\
\text { W }-)\end{array}$ & $\begin{array}{c}\text { YNTHALP } \\
\text { Y (-) }\end{array}$ & $\begin{array}{c}\text { FREQFA } \\
\text { C } / \text { gmol })\end{array}$ & $\begin{array}{c}\text { SOR }(-) \\
\text { W }(-)\end{array}$ & $\begin{array}{c}\text { Cumulative } \\
\text { oil recovery } \\
\left(\mathrm{m}^{3} * 10^{-6}\right)\end{array}$ & $\begin{array}{c}\text { HM } \\
\text { Error } \\
(\%)\end{array}$ \\
\hline 44 & -3.17 & -2.26 & 706.3 & 8.22 & 0.2008 & 2.29 & 3.62 \\
73 & -4.21 & -3.52 & 791.0 & 6.06 & 0.1902 & 2.40 & 4.03 \\
12 & & & & & & & \\
8 & -4.35 & 1.29 & 574.3 & 4.58 & 0.2126 & 2.16 & 5.20 \\
14 & -4.18 & -1.50 & 898.8 & 5.92 & 0.2152 & 2.13 & 5.35 \\
64 & -4.48 & -4.32 & 871.8 & 7.75 & 0.1978 & 2.32 & 5.67 \\
\hline
\end{tabular}


Highlights:

1. Core flooding experiments and modelling of an oil viscosity reducing microbe for EOR is considered.

2. A logistic growth model for the microbes is developed and incorporated in a commercial simulator.

3. Automatic history matching and artificial intelligence study are proposed to model MEOR activities to easily predict uncertainty.

4. Varying both the nutrient (yeast extract) concentration and shut-in period had less or no significant effect on the oil viscosity and subsequent recovery.

5. MEOR could enhance oil recovery significantly if a larger capillary number (between $10^{-5}$ and $10^{-3.5}$ ) is attained. 